\title{
CENTRALIDADES E TRANSFORMAÇÕES Avenida Rio Verde em Aparecida de Goiânia - Goiás (Brasil)
}

\author{
Evelyn Cristine Moreira Soares \\ Aluna do Doutorado da FAU / UNB - Planejamento Urbano e Regional \\ Docente da Escola de Artes e Arquitetura da PUC GOIÁS - Brasil \\ Pesquisa para Dissertação de Mestrado PPG Projeto e Cidade - Universidade Federal de Goiás \\ evycris@hotmail.com / arq.evelynsoares@gmail.com \\ Orientadora: Dra. Erika Cristine Kneib - Universidade Federal de Goiás \\ Agência Financiadora da Pesquisa de Mestrado: FAPEG \\ Apoio de Financiamento ao Evento: FAU / UNB
}

\section{RESUMO}

Apresenta o resultado da pesquisa realizada sobre a formação das centralidades do Município de Aparecida de Goiânia, sobretudo aquela localizada em uma região territorialmente periférica, em conurbação com o Município de Goiânia, a Capital, mas que se consolida como um dos principais subcentros do Município de Aparecida de Goiânia. Para tal, foram resgatados o desenvolvimento, a ocupação e a expansão territorial dos dois municípios, bem como o processo de metropolização que os envolve. Para a identificação das centralidades utilizou-se um método baseado em Especialistas. Somou-se ao método aplicado, 0 levantamento das características relacionadas ao subcentro da Avenida Rio Verde, quanto ao uso do solo, à acessibilidade e à geração de viagens. A análise considerou a influência sofrida pela implantação de grandes empreendimentos, os Polos Geradores de Viagens - PGV, que sempre impactam diretamente a formação destas centralidades e, consequentemente, determinam a mobilidade dos cidadãos e a acessibilidade à região.

Palavras-chave: Centralidades; Polos Geradores de Viagens, Conurbação, Uso do Solo, Mobilidade e Acessibilidade.

\section{ABSTRACT}

This thesis presents the results of research conducted on the formation of the centrality of the city of Aparecida de Goiânia, especially one located in a territorially peripheral region in conurbation with the city of Goiania, the capital, but that is consolidated as one of the sub-centers of city of Aparecida de Goiania. To this end, they were rescued development, occupation and territorial expansion of the two cities and the metropolises process involving them. For centralities used a method based experts. Added to the method applied, the survey of characteristics related to the sub-center of Rio Verde Avenue, the land use, accessibility and trip generation. The analysis considered the influence suffered by the implementation of large projects, the Polos Travel Generators - PGV, which always directly affect the formation of these centralities and hence determine the mobility of citizens and accessibility to the region.

Keywords: Centralities ; Polos Travel Generators, conurbation, Land Use, Mobility and Accessibility. 


\section{INTRODUÇÃO}

As cidades são uma das maiores produções da humanidade e a forma como esse espaço surge, se expande e se organiza tem motivado diversas reflexões por parte de várias ciências; diante da relevância do tema (CAMILO, 2014).

Nesta pesquisa, em específico, a região em estudo, periférica a dois municípios, Goiânia e Aparecida de Goiânia, apresenta características de centralidade: infraestrutura, acessibilidade, qualidade de vida e facilidade de deslocamento. O recorte pretendido aborda a Avenida Rio Verde da cidade de Aparecida de Goiânia, principalmente nos seus aspectos de ocupação e desenvolvimento no entorno do Shopping Buriti, com ênfase no uso e ocupação do solo, voltados à formação de novas centralidades, à mobilidade dos cidadãos e à acessibilidade.

Vale adiantar que dois aspectos são considerados nesta investigação: o primeiro, o fato de que Aparecida de Goiânia se desenvolveu próxima a uma capital, Goiânia, que apresenta um forte processo de crescimento, como descreve Villaça (2001), fato que gerou o surgimento de vários centros urbanos no território do Município de Aparecida de Goiânia, áreas de conurbação e de grande segregação espacial. O segundo aspecto, alia à formação desses novos centros a comprovação de que os polos geradores de viagem (PGVs), segundo Kneib (2004), impactam não apenas o tráfego viário, mas, também, o uso do solo (tipos de atividades), a densidade e o valor do solo. Eles são de extrema importância para a formação dessas novas centralidades. Por essas razões, para um estudo eficaz da área em pesquisa, faz-se necessária a descrição dos impactos no ambiente urbano, causados por tais empreendimentos, no quesito uso do solo, densidade e geração de viagens, além da análise das características de acessibilidade e mobilidade.

Por se tratar da Capital, Goiânia, e da conurbação existente com um município que faz parte da Região Metropolitana, Aparecida de Goiânia, é importante, também, abordar a questão das regiões de conurbação metropolitana. Geralmente as regiões metropolitanas formam aglomerações urbanas, em uma grande área constituída pela cidade-núcleo e as cidades adjacentes, compondo uma conurbação. O processo de conurbação é caracterizado pelo crescimento que expande a cidade, prolongando-a para fora de seu perímetro, de tal maneira a absorver outras cidades (VILLAÇA, 2001).

\subsection{Problema}

O problema explorado pelo presente trabalho consiste em registrar e analisar quais variáveis e vetores (crescimento populacional, uso e ocupação, acessibilidade, mobilidade, polos geradores de viagens, deslocamentos) influenciaram na formação de uma região periférica e em área de conurbação do Município de Aparecida de Goiânia, que possui características diferenciadas do restante do território urbano.

As perguntas que geraram esta pesquisa foram: A região localizada nos limites do território municipal se conforma como uma centralidade ou uma periferia? As características presentes no meio ambiente urbano foram influenciadas pela conurbação com a capital, Goiânia? Qual o Impacto no uso e ocupação do solo decorrente da implantação de um PGV nessa região? Quais os fatores relacionados à infraestrutura viária e de transportes que colaboram com a caracterização dessa região? Ainda, como questionamentos secundários, as perguntas para as quais esta pesquisa buscou respostas foram: Quais as características de desenvolvimento relativas à expansão territorial, uso e ocupação do solo, acessibilidade e geração de viagens que são marcantes na formação e consolidação dessa região?

\subsection{Hipótese}

Para solucionar o problema proposto, adota-se a hipótese de que três fatores, em diferentes escalas de importância e influência, impactaram diretamente no desenvolvimento e ocupação urbana da região na Avenida Rio Verde, atribuindo características de centralidade à sua área de influência, deixando a região de ser considerada apenas uma periferia, passando a conformar uma centralidade, localizada em uma área de conurbação na região metropolitana de Goiânia. São eles: O crescimento e expansão da capital na região sul; A implantação de um PGV (Shopping Center); O Planejamento Urbano: infraestrutura viária, de transportes e uso do solo.

\subsection{Objetivo Geral}

Em uma escala de análise espacial e temporal, fazer uma investigação da região formada na área de 
conurbação que ocorre na Avenida Rio Verde, entre Goiânia e Aparecida de Goiânia, no entorno do Buriti Shopping, constatando ou não a consolidação de uma centralidade, considerando, para tanto, o principal fator de influência a implantação do empreendimento gerador de viagens, bem como os impactos associados a ele, decorridos no ambiente urbano.

Essa análise se dá com o levantamento de dados conceituais e do histórico de crescimento e expansão urbanos, com uma com uma análise comparativa, no quesito espacial e temporal (antes e após à implantação do empreendimento), com o intuito de evidenciar as transformações ocorridas no meio ambiente urbano e a confirmação da região como centralidade ou periferia.

\subsection{Justificativa}

A relevância do tema se confirma à medida que se aborda a temática da expansão urbana relacionada aos instrumentos de gestão e à implantação de polos geradores de viagens, cujos impactos no meio ambiente urbano são profundos, tanto relacionados ao trânsito e sistema viário, quanto ao uso e ocupação do solo. Esse estudo visa contribuir para a ampliação de estudos e pesquisas que investiguem a dinâmica intraurbana relacionada aos empreendimentos geradores de viagens, permitindo diretrizes para ocupação do solo urbano em diferentes áreas a partir de centralidades, com mix de usos, objetivando melhor aproveitamento de potencialidades e reestruturação do sistema viário e transportes.

Justifica-se, pois, esta pesquisa, o fato de que a região tomada por estudo foi considerada, por muito tempo, como periferia isolada e marginalizada, dos municípios de Goiânia (capital) e Aparecida de Goiânia. Chamada por Arimatéia (2003) como "Terra do Nem" - Nem Goiânia, nem Aparecida de Goiânia - atualmente possui características diferenciadas de uso e ocupação do solo. Diante disso, o foco desta pesquisa envolve a formação do espaço urbano da Avenida Rio Verde no entorno do Shopping Buriti, investigando sua caracterização, seu desenvolvimento e sua transformação ao longo dos anos. Trata-se de uma região inserida em área de conurbação com a Capital de Goiás, pertencente à Região Metropolitana, alvo de investimentos e projetos de corredores exclusivos de transporte público, mobilidade da população e acessibilidade à região.

\subsection{Metodologia da Pesquisa e Estrutura do Trabalho}

A metodologia de pesquisa proposta para a realização do trabalho é de natureza quantitativa, de caráter descritivo e exploratório, baseada em técnicas de documentação direta como: pesquisa em campo, consulta exploratória com profissionais e técnicos da área relacionada ao objeto de pesquisa e análise de mapas; bem como indireta, por meio de pesquisa bibliográfica e documental, além de englobar um estudo de caso.

O desenvolvimento desta investigação se dá, inicialmente, com a elaboração do referencial teórico conceitual a ser utilizado para o desenvolvimento das análises pretendidas. Para a realização do estudo de caso, considerar-se-ão três escalas de análise, com a intenção de uma avaliação das estruturas urbanas, que serão melhor descritas do item Referencial Metodológico.

\section{REFERENCIAL BIBLIOGRÁFICO}

\subsection{Centros e Subcentros Urbanos}

O tema centros urbanos e centralidades foi motivo de estudo, análise e discussão para diversos autores e estudiosos. Alguns descrevem o centro com duas funções principais: primeiro a integradora e simbólica, concentrando valores e significados, estando, entre outros, os autores Levebvre (1978) e Castells (1983); segundo, descrevem o centro como uma área dinâmica, onde se encontram locais de comércio e trabalho, vinculando-a a um aspecto de acessibilidade, como Villaça (2001), Kneib (2008), Corrêa (1995), Sposito (2001), Serpa (2014). Neste trabalho serão tratados os subcentros nessa segunda perspectiva, apresentandose a seguir os principais conceitos discutidos por alguns desses autores.

De acordo com Corrêa (1995), esses núcleos se desdobram em áreas (regionais, bairros) ou em eixos (ruas comerciais de bairros), de comércios e serviços. Kneib (2004) apresenta os tipos de centros definidos por Bird (1977), que podem ser: centros concêntricos (áreas de alta acessibilidade para pedestres e automóveis); centros lineares (acessibilidade linear canalizada pelas vias de circulação); centros especiais (subcentros). 
Kneib et al (2012) afirma que a estrutura espacial urbana é composta por um conjunto, ou rede, de centros e subcentros, destaca que as áreas centrais possuem a característica simbólica (apesar de difícil mensuração), mas também enfoque na acessibilidade, seja pela infraestrutura viária ou pela existência de linhas de transporte coletivo; além de se destacarem pela concentração de atividades, "com profunda relação com o número de viagens geradas", sendo áreas atribuídas de uma maior valor do solo (KNEIB, 2008: 33). Atribui, ainda, o PGV (Polos Geradores de Viagens) um elemento de contribuição para a formação ou consolidação de novas centralidades. A autora ainda afirma que a identificação e definição dos subcentros urbanos estão relacionadas com a definição de diretrizes para o ordenamento territorial e de transportes, além da avaliação da acessibilidade nesses subcentros e a mobilidade das pessoas que se destinam a eles.

\subsection{Periferização no Brasil}

A consequência dos modelos de urbanização segregado e espraiado é que as cidades, sobretudo as grandes, ocupam, de um modo geral, vastas superfícies, entremeadas de vazios", sendo caracterizadas espacialmente: pelo "tamanho urbano; [pelo] modelo rodoviário; [pela] carência de infraestrutura; [pela] especulação fundiária e imobiliária; [pelos] problemas de transporte, extroversão e periferização da população, gerando, graças às dimensões da pobreza e seu componente geográfico, um modelo especifico de centro-periferia" (SANTOS, 1993, p. 95).

Essa realidade, de acordo com Santos (1993), sustenta e alimenta um círculo vicioso de crescimento: as cidades são grandes porque há especulação, há especulação porque há vazios, há vazios porque as cidades são grandes. O modelo rodoviário urbano é fator de crescimento disperso e do espraiamento, acentuando o problema de acesso a terra e à habitação, conduzindo à periferização da população mais pobre e induzindo, novamente, o aumento do tamanho urbano. Repetindo, a especulação é alimentada pela escassez de serviços em diversas frações do território (periferias), causa a diferenciação da valorização do solo e retoma a questão do acesso a terra e às habitações.

Todo esse quadro pintado por Santos (1993) demonstra o desaparecimento da escala do pedestre, a facilidade de aquisição do automóvel, sendo as periferias uma parte da metrópole (Mumford, 1998), e dentro deste contexto de metrópole inescapável, citada pelo autor, que se discutirá o processo de periferização em áreas de conurbação, situadas em regiões metropolitanas, característica da região pesquisada.

\subsection{Conurbação e Metropolização}

Para que fique claro o que vem a ser conurbação, Villaça (2001) a define como "a fusão de áreas urbanas". O autor ainda a explicita como sendo uma única cidade dividida em dois municípios, pois as características comerciais, econômicas, construtivas, de ambos os espaços, são as mesmas, de tal maneira que se torna um único espaço territorial, porém dividido em dois espaços administrativos.

Geddes (1994), considerado o primeiro autor a utilizar a denominação "conurbação". Busca em seus estudos exprimir os avanços e homogeneizações do tecido urbano, descrevendo as novas formas de agrupamento demográfico, que levam a novas formas de agrupamento social, atentando para as necessidades de novas formas de governo e administração para essas áreas.

Villaça (2001) associa ao processo de conurbação ocorre, na maioria das vezes, o processo de metropolização. Uma cidade-núcleo, considerada a principal, absorve e/ou gera outros núcleos urbanos à sua volta, às vezes pertencentes a outras unidades politico-administrativas, formando um tipo particular de cidade. O autor afirma ser essa absorção um processo lento, resultado da crescente transformação de uma área urbana, e acontece quando as cidades desenvolvem uma intensa vinculação socioeconômica, causando transformações tanto no núcleo absorvido, quanto no que absorve.

\subsection{Shopping Center como PGV (Polo Gerador de Viagens)}

A nomenclatura PGV é aplicada a empreendimentos que, segundo o Denatran, atraem ou produzem grande número de viagens com consequências negativas na circulação viária no entorno imediato do local de implantação do empreendimento, prejudicando a acessibilidade de toda a região, além de agravar as condições de segurança de veículos e pedestres. (DENATRAN, 2001)

Gonçalves et al (2012) afirmam que, conceitualmente, esses empreendimentos incluem viagens motorizadas e não motorizadas, além das viagens geradas pelo transporte público, sendo considerados os impactos de 
abrangência socioeconômica e na qualidade de vida da população, abrangendo desde a circulação de pedestres e veículos à outros elementos voltados ao espaço urbano.

A classificação dos PGVs é realizada devido a seu potencial de impacto, a partir do cálculo de previsão da demanda futura de tráfego, realizada com base na geração de viagens ocasionada pelo empreendimento, no horário de pico (horário com maior fluxo de viagens geradas pelo empreendimento). Dessa maneira determina-se, o que Gonçalves et al (2012) denominam de "abrangência espacial e magnitude relativa dos impactos".

Kneib (2012) ressalta a relação entre PGVs e centralidades, descrevendo o processo ocorrido em áreas centrais como sendo estabelecido em um processo cíclico, iniciado pela atratividade do empreendimento, resultando em um grande número de viagens e em uma alteração dos padrões de uso e ocupação do solo, com consequente aumento de novas construções na região, com aumento da demanda de terrenos e valorização do solo, atraindo mais atividades, mais construções, e consequentemente um número adicional de viagens.

A implantação de empreendimentos de grande porte, os shoppings, pode causar impactos profundos nas atividades urbanas, devido a seu grande poder de atratividade, ocasionando o crescimento populacional e 0 aumento do número de viagens por automóvel, alterando toda a estrutura local. Segundo o Denatran (2001), há um deslocamento de atividades econômicas, antes implantadas nos centros das cidades, para novas centralidades comerciais, como exemplo os shopping centers, que se instalados em áreas afastadas podem levar consigo a ampliação dos problemas do trânsito.

\section{REFERENCIAL METODOLÓGICO}

Este subitem descreve as metodologias aplicadas para análise em diferentes etapas da pesquisa, organizadas em três escalas, conforme demonstrado no Quadro 1.

\begin{tabular}{|c|c|c|c|}
\hline ESCALA & ANÁLISE & OBJETIVOS & $\begin{array}{l}\text { REFERENCIAL } \\
\text { MEIODOLÓGICO }\end{array}$ \\
\hline MACRO & $\begin{array}{c}\text { Região de estudo: } \\
\text { Conurbação / } \\
\text { centralidades de Goiânia } \\
\text { e Aparecida }\end{array}$ & $\begin{array}{l}\text { Caracterizar a região de } \\
\text { estudo e compreender } \\
\text { seus processos de } \\
\text { ocupação e de expansão } \\
\text { urbanas }\end{array}$ & $\begin{array}{l}1 \text { Histórico de ocupação; } \\
2 \text { Plano Diretor; } \\
\text { 3. Processo de Urbanização e } \\
\text { Ocupação do espaço } \\
4 \text { Identificação das centralidades } \\
\text { dos Municipios de Goiânia e } \\
\text { Aparecida de Goiânia }\end{array}$ \\
\hline MESO & $\begin{array}{c}\text { Centralidade da Avenida } \\
\text { Rio Verde }\end{array}$ & $\begin{array}{l}\text { Identificar a região como } \\
\text { uma centralidade, bem } \\
\text { como suas características } \\
\text { e processo de } \\
\text { desenvolvimento }\end{array}$ & $\begin{array}{l}\text { 5. Delimitação da Região de } \\
\text { Estudo; } \\
6 \text {. Uso do solo da região de } \\
\text { estudo } \\
\text { 7. Formação da Centralidade da } \\
\text { região de estudo - Centralidades } \\
\text { em Conurbação }\end{array}$ \\
\hline MICRO & $\begin{array}{c}\text { Área de influência direta } \\
\text { do PGV-Shopping } \\
\text { Center }\end{array}$ & $\begin{array}{l}\text { Caracterizar a influência } \\
\text { de um PGV na formação } \\
\text { da centralidade e suas } \\
\text { consequências na } \\
\text { mobilidade e } \\
\text { acessibilidade à região }\end{array}$ & $\begin{array}{l}\text { 8. Relação de uso e ocupação } \\
\text { do solo no entorno do PGV, em } \\
\text { três datas: } 1992,2006 \text { e } 2014 \\
\text { (observando os aspectos: cheio } \\
\text { /vazios, uso comercial / } \\
\text { residencial) }\end{array}$ \\
\hline
\end{tabular}

A diferenciação dessas escalas de análises se faz importante pela necessidade de instrumentalização e percepção do todo, como também de particularidades. Romero (2009) afirma ser possível o entendimento do espaço a partir de três aspectos urbanos: a edificação, as redes (fluxos) e a massa (entorno, conjunto urbano). Romero (2002) estabelece, a partir de variáveis dimensionais, territoriais, organizacionais, três subdivisões de escalas urbanas: macro, meso e micro escalas. 
A importância da análise por meio das escalas tem como principal objetivo uma caracterização e espacialização eficaz (gargalos, segregações, impactos, contradições), possibilitando maior percepção das dinâmicas de produção e reprodução do urbano e associadas aos estudos de diferentes condicionantes (variáveis, vetores, atributos) que agem sobre a cidade e que compõem o espaço urbano e regional (exercendo maior ou menor impacto na urbanização), oferecem diversidade de possibilidades para as ações e propostas de intervenções urbanísticas que envolvem o espaço e vislumbram um planejamento urbano e regional integrado, produzindo aplicações em curto, médio e longo prazo. Nesta pesquisa, considera-se a escala espacial e a escala conceitual.

\subsection{Identificação dos subcentros dos municípios de Aparecida e de Goiânia pelo Método dos Especialistas}

A região definida para estudo está no entorno da Avenida Rio Verde, que faz limite entre Goiânia e Aparecida de Goiânia. A característica principal da região é a de atrair pessoas, sendo, portanto, uma centralidade no Município, possivelmente a de maior grau de influência e importância em relação às demais.

Para a comprovação dessa hipótese, isto é, de que a área em estudo é uma centralidade, mesmo estando localizada em uma região periférica e de conurbação; bem como confirmar seu grau de influência nos municípios que a envolvem, é necessária a identificação dos subcentros urbanos desses municípios. Posteriormente, no Capítulo IV é abordado o principal aspecto de influência na transformação da região em centralidade, que, já antecipando, se deu após a implantação de um polo gerador de viagens: o Buriti Shopping.

O Método dos Especialistas é baseado na Técnica Delphi, utilizada para identificar espacialmente subcentros de qualquer município, a partir do consenso entre especialistas. O embasamento no conhecimento dos especialistas oferece credibilidade ao método e torna, portanto, o processo de seleção deles um passo muito importante para a aplicação metodológica. Kneib (2008) declara que não existem regras específicas para a escolha dos especialistas, "uma vez que o método se apoia na experiência, sabedoria e criatividade de um conjunto de especialistas; e no fato de que o julgamento coletivo é supostamente melhor que qualquer julgamento individual". Também não determina um número exato de especialistas, mas aconselha não ser utilizada uma amostra pequena, pois pode ocasionar uma escassez na geração de ideais. Ferraz (1993), entretanto, ressalta que a formalização do consenso de opiniões sobre determinado assunto não revela verdades absolutas e imutáveis.

Para a aplicação metodológica, algumas ferramentas são utilizadas, tanto para auxiliar o especialista a manter o foco do processo metodológico (definição das centralidades e grau de importância), como para a manipulação desses dados de forma que se chegue a um produto final entre os especialistas. Uma das ferramentas de auxilio à aplicação do método são os questionários entregues aos especialistas. De acordo com o método de Kneib (2008, p. 118), "foi necessário um trabalho de adaptação-inovação no método: a inserção da análise espacial nos questionários" e a definição de uma escala de pontos para mensurar o grau de importância dos subcentros.

Outra ferramenta utilizada nessa pesquisa, apresentada no item 4, para a análise espacial, foi o SIG Sistemas de Informação Geográfica, para a manipulação dos dados (de todos os especialistas). Assim, é constituído um ferramental amplamente utilizado para planejamentos urbano e de transportes. Dantas et al (1996) definem um SIG como "a integração entre banco de dados, recursos humanos, hardware adequado e ferramental para análise espacial".

\subsection{Procedimento Sistematizado de Análise da influência de um PGV na região de Estudo}

$\mathrm{Na}$ última etapa de pesquisa (item 5) é aplicado o procedimento metodológico proposto por Kneib (2004, 2012), para a definição da correlação entre a implantação de novos empreendimentos geradores de viagens, além de outros grandes empreendimentos voltados ao transporte coletivo, e o desenvolvimento das regiões onde estão inseridos.

Compondo essa reflexão é feito o estudo do uso e ocupação do solo da região pesquisada, incluindo o mapeamento dos vazios existentes no entorno do empreendimento pesquisado. Assim, é possível comparar as situações de antes da implantação, do período de implantação e da atualidade, para que seja confirmada a hipótese de que o PGV Buriti Shopping trouxe característica de centralidade, ao local. Ainda são levantados 
os percentuais pertinentes a cada tipo de uso do solo, comercial ou residencial, para a análise de mudança de utilização da área.

A comprovação de que os polos geradores de viagem impactam o uso do solo (em relação aos tipos de atividades), a densidade e o valor do solo é de extrema importância para a constatação da formação de novas centralidades. A investigação ora apresentada é realizada por meio da análise de ocupação da área de influência imediata do empreendimento Buriti Shopping, abordando em três etapas as transformações ocorridas na ocupação do solo: a primeira de análise de áreas vazias, delimitada a 500 metros de raio do local onde foi implantado o Shopping, correspondendo a três períodos: 1992, 2006 e 2014; a segunda, para complementar as análises, a de avaliação da situação atual em dois panoramas: a) o das atividades, com a caracterização do uso atual do solo, num raio ampliado, de $1000 \mathrm{~m} \mathrm{e} \mathrm{b)} \mathrm{o} \mathrm{da} \mathrm{acessibilidade,} \mathrm{a} \mathrm{partir} \mathrm{da}$ situação das vias do entorno quanto aos aspectos de fluidez e nível de serviços e, ainda, do terminal de ônibus (transporte coletivo).

Os levantamentos apresentados têm como fonte a pesquisa de campo (in loco), dados descritos no Plano Diretor de Aparecida de Goiânia e, também, ferramentas modernas de informação, (SIG). Os resultados são apresentados por meio de mapas temáticos, que demonstram os impactos associados, em situação anterior e posterior à execução do empreendimento (shopping center), conforme delimitações temporais estabelecidas. Os mapas são denominados Ocupação (cheios e vazios) e Tipo de Ocupação.

\section{DEFINIÇÃo E CARACTERIZAÇÃO DA ÁREA DE ESTUDO}

Nesta pesquisa, em específico, a região em estudo, periférica a dois municípios, Goiânia e Aparecida de Goiânia, apresenta características diferenciadas: infraestrutura, acessibilidade, qualidade de vida e facilidade de deslocamento. Goiânia é a capital do Estado de Goiás, caracterizada como uma Metrópole, cuja área de influência engloba 19 municípios mais a capital (Figura 1), se destacando Aparecida de Goiânia pela população, que segundo o IBGE (2013) se aproximava de 490.000 habitantes.
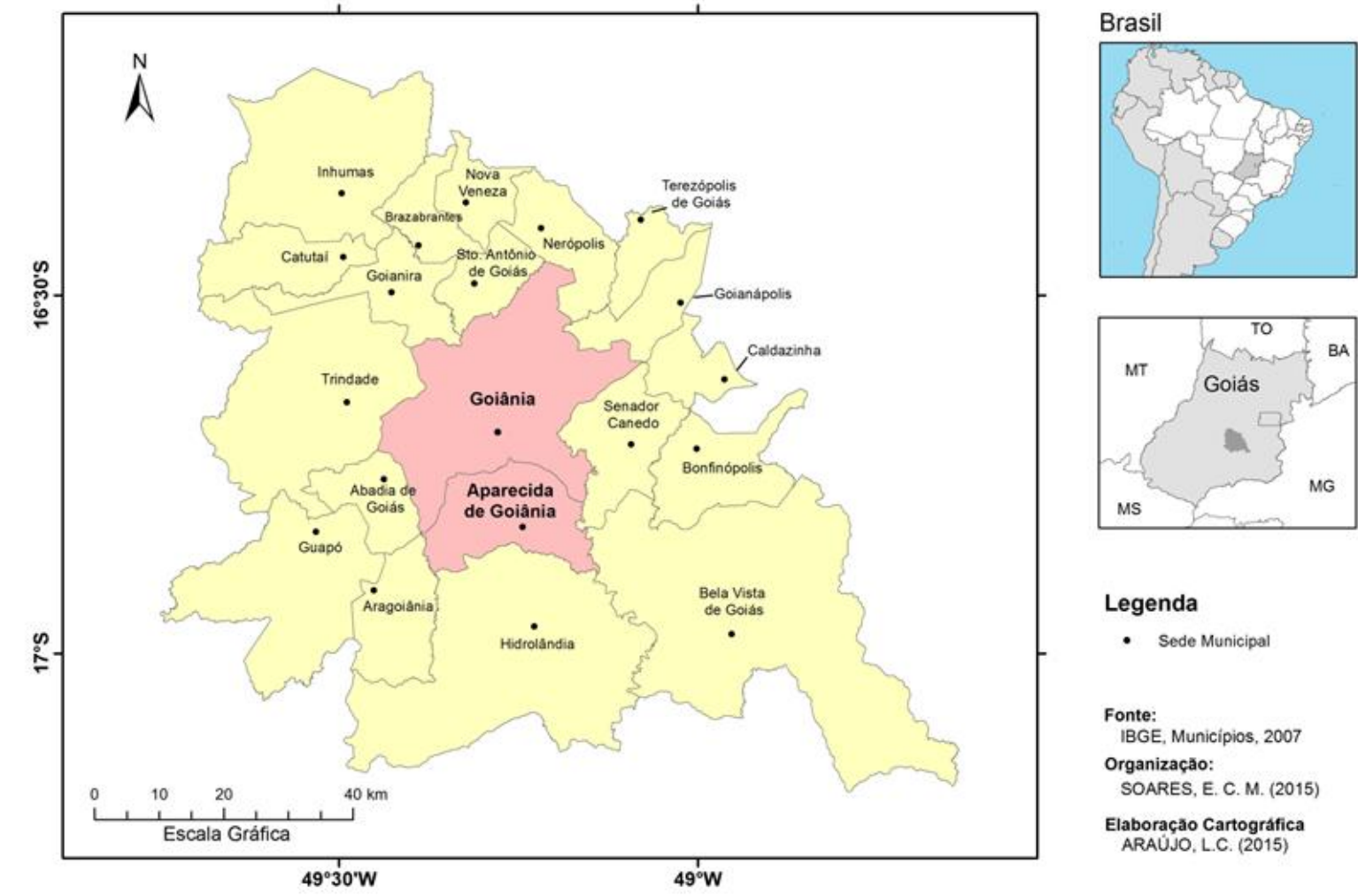

Figura 1: Região Metropolitana De Goiânia

Para se fazer possível uma análise das regiões periféricas da cidade de Aparecida de Goiânia (ficando limitada neste estudo à Avenida Rio Verde), se torna indispensável o contexto do desenvolvimento e fundação da capital Goiânia, sua expansão territorial e a formação da sua Região Metropolitana. De acordo com Geddes (1994), "a cidades não são mais unas, se entrelaçam formando-se cidades-regiões, densificando suas 
estruturas, tornando complexos os elementos que incidem sobre elas" (PINTO, 2009).

A emancipação de Aparecida de Goiânia se deu com a Lei Estadual no 9.927, de 14 de novembro de 1963. Não se pode deixar de enfatizar a questão dos vazios na formação urbana de Aparecida de Goiânia, que se desenvolveu, segundo Camilo (2014), de forma fragmentada e desarticulada, com um grande descompasso entre o contingente populacional e o quantitativo de terrenos.

Paulatinamente, Aparecida de Goiânia se firmava como periferia precária da Capital. Nesse processo de periferização e conurbação que tomava corpo, espacializava-se a divisão social do trabalho no espaço metropolitano, cabendo a Goiânia o papel de centro de comércio e serviços e a Aparecida de Goiânia, não só o papel de repositório da mão de obra não especializada, mas também à exploração de recursos naturais na região da Serra das Areias, na região sudoeste do município, que forneceu areia e saibro à indústria da construção da Capital do Estado e da Capital Federal. (CAMILO, 2014, p. 67).

Em meados da década de 1960, já era possível identificar a aglomeração da Vila Brasília na Região Norte do Município, junto à divisa com a Capital, "um princípio do que viria a se consolidar como conurbação, antes mesmo da existência do Município. Entre a aglomeração da Vila Brasília e o centro pioneiro, uma enorme área sem qualquer ocupação". (CAMILO, 2014, p. 55). Em 1980, dos 42.632 habitantes do Município, 31.926 habitantes localizavam-se no distrito de Vila Brasília (CAMILO, 2014 p. 63).

Ao longo das décadas após a emancipação do Município, vários loteamentos foram aprovados; conforme Assunção (2013), cerca de 140 nas décadas de 1970 e 1980. É adequado destacar aqui, os situados próximo à conurbação com a Região Sudoeste da Capital, que marcam até hoje o território intraurbano do Município, seguindo o Quadro 2.

\section{Quadro 2: Alguns Loteamentos aprovados próximos à Avenida Rio Verde}

\begin{tabular}{ll|}
\hline Ano & Aprovação do Loteamento \\
\hline 1953 Vila Mariana e Jardim Nova Era \\
\hline 1955 Jardim Helvécia, Bairro Ilda, Cidade Satélite São Luiz, Vila São Tomás, \\
Jardim Luz, Vila Brasilia, Vila Real, Vila São Joaquim \\
\hline 1956 Jardim das Esmeraldas \\
\hline 1957 Jardim Itapuã, Bairro Santo Antônio, Jardim Transbrasiliano \\
1974 Setor dos Afonsos \\
\hline 1994 Jardins Viena \\
\hline 1999 Polo Empresarial \\
\hline
\end{tabular}

De acordo com Pinto (2009), esses novos bairros parcelados no Distrito de Aparecida de Goiânia se concentravam na porção sul de Goiânia (Figura 2), apresentando, assim, maior relação funcional entre o Distrito e a Capital. Porém, ambas as cidades apresentavam tecido descontínuo.

A Avenida Rio Verde é caracterizada pela presença de grandes empreendimentos comerciais, como será confirmado no decorrer da pesquisa. Ela dá acesso direto aos condomínios horizontais implantados no Município, denominados Jardins Viena e Jardim Mônaco; à Cidade Empresarial; e fácil acesso ao Terminal Garavelo (GO 040) e à Vila Brasília (Av. São Paulo). A referida Avenida era a antiga estrada para a cidade de Rio Verde, mas atualmente faz ligação com importantes eixos viários como: a GO-040, inclusive possibilita o fluxo para a Av. T-9; a Av. São Paulo, tornando fácil o acesso ao Anel Viário (ligação da BR-060 à BR-153); além de possibilitar também a vazão do fluxo para as importantes Avenidas 85 e T-63, ambas da cidade de Goiânia. É exatamente por isso considerada por alguns autores, como Camilo (2014) e Pinto (2009), como a principal via comercial de Aparecida de Goiânia. No entanto, a região se caracteriza, também, pela presença de edifícios residenciais, tanto na área territorial de Goiânia, como na do próprio Município ao qual pertence. 


\section{Evolução dos loteamentos próximos a Avenida Rio Verde}

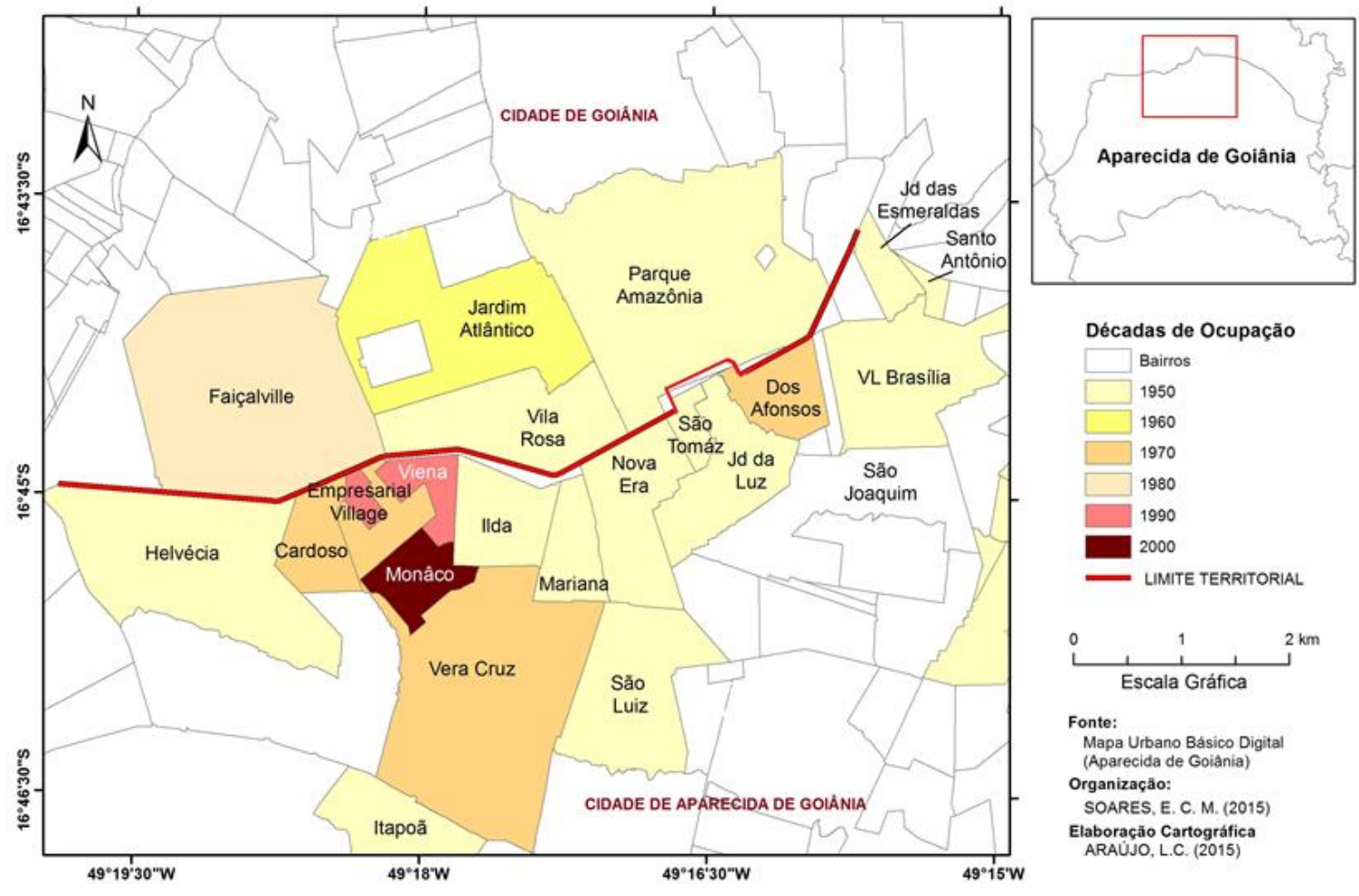

Figura 2: Décadas De Ocupação Dos Loteamentos Próximos À Avenida Rio Verde

\section{APLICAÇÃO METODOLÓGICA PARA IDENTIFICAÇÃO DE CENTRALIDADES}

A metodologia é baseada na Técnica Delphi, utilizada para identificar espacialmente subcentros de qualquer município, se baseia na busca de um consenso para o tema abordado, levando em consideração o uso do conhecimento de especialistas (anônimos) sobre o assunto, a aplicação interativa de várias rodadas de questionários para a concordância e oferecendo feedback a cada interação. O uso de especialistas oferece credibilidade ao método, e torna, portanto, o processo de seleção desses especialistas um passo muito importante para a aplicação metodológica. As etapas da aplicação do procedimento metodológico estão descritas no Quadro 3.

\subsection{Resultados}

O resultado da sobreposição e mediana dos dados dos dez novos mapas apresentados pelos especialistas (feitos com base no questionário aplicado) foi o Mapa Produto da segunda e rodada (Figura 3), que não obteve mudanças do mapa produto da primeira rodada, sendo finalizado o processo nessa etapa pela porcentagem de concordância nas questões geradas no questionário aplicado, tendo sido de $75,75 \%$.

O mapa produto apresentado foi o resultado das etapas da pesquisa, tendo sido a identificação por parte dos especialistas das centralidades existentes no município. Após o lançamento das informações levantadas para programa SIG e realização de mediana dos resultados, foram identificadas 09 áreas, denominadas como centralidades, com diferentes graus de importância (diferenciado pelas cores da legenda), sendo:

A - Centro;

B - Av. Independência, próximo ao Shopping;

C - Av Independência, Cidade Livre;

D - Jd. Tiradentes;

E - Setor Garavelo, Jd. Tropical;
F - Bairro Ilda, proximidades Cidade Empresarial e Jardins Mônaco;

G - Buriti Shopping e entorno;

H - Vila Brasília;

I - Vila Santa Luzia. 
Quadro 3: Resumo Da Metodologia Aplicada

\begin{tabular}{|c|c|c|c|c|}
\hline \multicolumn{2}{|c|}{ Fase } & \multirow[t]{2}{*}{ Etapas } & \multirow{2}{*}{\begin{tabular}{|l|} 
Metodologia \\
Definição de quantidade de \\
participantes;
\end{tabular}} & \multirow{2}{*}{$\begin{array}{l}\text { Objetivos } \\
\text { Seleção de especialistas } \\
\text { com perfis adequados à } \\
\text { execução da pesquisa. }\end{array}$} \\
\hline \multirow{3}{*}{ 永 } & \multirow{3}{*}{ 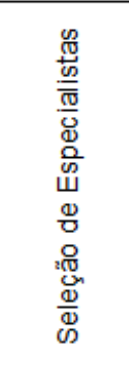 } & & & \\
\hline & & \multirow{2}{*}{$\begin{array}{l}\text { Estabelecer } \\
\text { critérios para a } \\
\text { escolha dos } \\
\text { especialistas. }\end{array}$} & $\begin{array}{l}\text { Critério: conhecimento e } \\
\text { domínio, prático ou teórico do } \\
\text { municipio; }\end{array}$ & $\begin{array}{l}\text { Contato e } \\
\text { Agendamento. }\end{array}$ \\
\hline & & & $\begin{array}{l}\text { Ser servidor municipal e estar } \\
\text { ligado à atividades que } \\
\text { proporcionem conhecimento } \\
\text { da Macrozona Urbana do } \\
\text { Município; }\end{array}$ & $\begin{array}{l}\text { Preparação para } \\
\text { Primeira Rodada. } \\
\text { Uniformizar, entre os } \\
\text { especialistas, as } \\
\text { definições e } \\
\text { características } \\
\text { trabalhadas no tema } \\
\text { subcentros. } \\
\end{array}$ \\
\hline \multirow{7}{*}{ 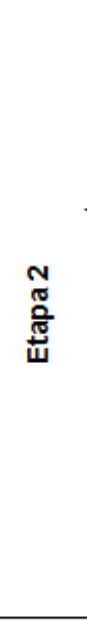 } & \multirow{3}{*}{ 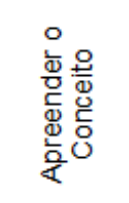 } & \multirow{3}{*}{$\begin{array}{l}\text { Elaboração de } \\
\text { Conceitos que } \\
\text { envolvem a } \\
\text { pesquisa }\end{array}$} & Identificação do Objetivo; & \multirow{3}{*}{$\begin{array}{l}\text { Uniformizar, entre os } \\
\text { especialistas, as } \\
\text { definições e } \\
\text { características } \\
\text { trabalhadas no tema } \\
\text { subcentros. }\end{array}$} \\
\hline & & & $\begin{array}{l}\text { Conceito e características de } \\
\text { subcentros; }\end{array}$ & \\
\hline & & & Tipologia das áreas centrais; & \\
\hline & \multirow{4}{*}{ 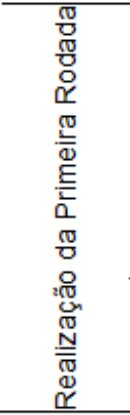 } & \multirow{3}{*}{$\begin{array}{l}\text { Produção individual } \\
\text { por cada } \\
\text { especialista de um } \\
\text { mapa com a } \\
\text { identificação das } \\
\text { centralidades do } \\
\text { município }\end{array}$} & Aplicação de Questionário; & \multirow{2}{*}{$\begin{array}{l}\text { Identificação dos } \\
\text { subcentros. }\end{array}$} \\
\hline & & & \begin{tabular}{|l} 
Definição Metodológica para \\
identificação dos subcentros;
\end{tabular} & \\
\hline & & & $\begin{array}{l}\text { Atribuição de Escala de } \\
\text { Pontos para diferenciação do } \\
\text { grau de importância do } \\
\text { subcentro (método Delphi) na } \\
\text { cidade; }\end{array}$ & $\begin{array}{l}\text { Mensuração do grau de } \\
\text { importância de cada } \\
\text { subcentro em relação } \\
\text { aos demais. }\end{array}$ \\
\hline & & $\begin{array}{l}\text { Geração de Mapa } \\
\text { Produto da Primeira } \\
\text { Rodada }\end{array}$ & $\begin{array}{l}\text { Lançamento dos dados no } \\
\text { programa SIG; }\end{array}$ & $\begin{array}{l}\text { Mapa produto da } \\
\text { mediana das } \\
\text { informações mapeadas } \\
\text { pelos especialistas. }\end{array}$ \\
\hline Etapa & $\begin{array}{l}\text { Demais } \\
\text { Rodadas }\end{array}$ & $\begin{array}{l}\text { Consenso entre } \\
\text { Especialistas }\end{array}$ & Aplicação de Questionário; & $\begin{array}{l}\text { Mapa produto do } \\
\text { consenso entre } \\
\text { Especialistas. }\end{array}$ \\
\hline
\end{tabular}

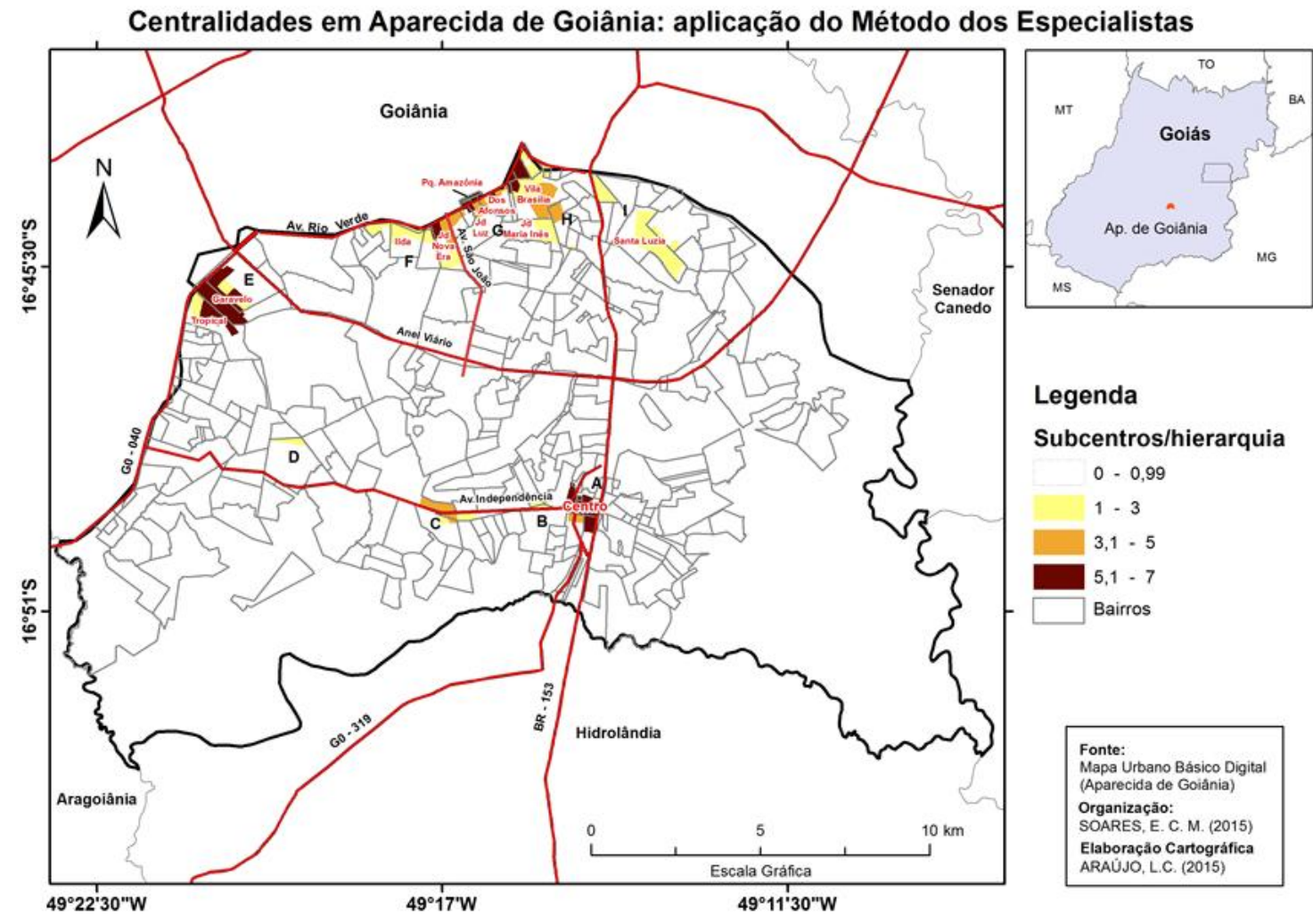

Figura 3: Identificação Das Centralidades De Aparecida De Goiânia Pelo Método Dos Especialistas. 


\subsection{Centralidades em Área de Conurbação}

Diferentemente de outras centralidades em área de conurbação - como a do Setor Garavelo, cuja centralidade se encontra apenas no espaço territorial do Município de Aparecida de Goiânia, com previsão de uma possível mudança, devido à futura consolidação da região de implantação do Portal Sul Shopping e do Condomínio fechado Jardins Lisboa - é importante observar que a área de estudo se apresenta como centralidade, na pesquisa realizada por Kneib (2014) para o Município de Goiânia, e também aqui, nesta pesquisa realizada para o Município de Aparecida de Goiânia.

Para a análise da região pesquisada, foi conveniente fazer a junção dos mapas produto das centralidades dos dois municípios, Goiânia (estudo realizado por Kneib, 2014) e Aparecida. Resulta dessa ação a centralidade de estudo, a partir de agora denominada como Centralidade da Avenida Rio Verde, conforme Figura 4. Esta centralidade se constitui por uma parte do Parque Amazônia, de Goiânia, e por bairros lindeiros à Av. Rio Verde, de Aparecida de Goiânia, tais como: o Setor dos Afonsos, a Vila São Tomaz, o Jardim Nova Era, o Jardim Luz, e especialmente pela área do empreendimento Buriti Shopping, principal agente fomentador dessa centralidade.

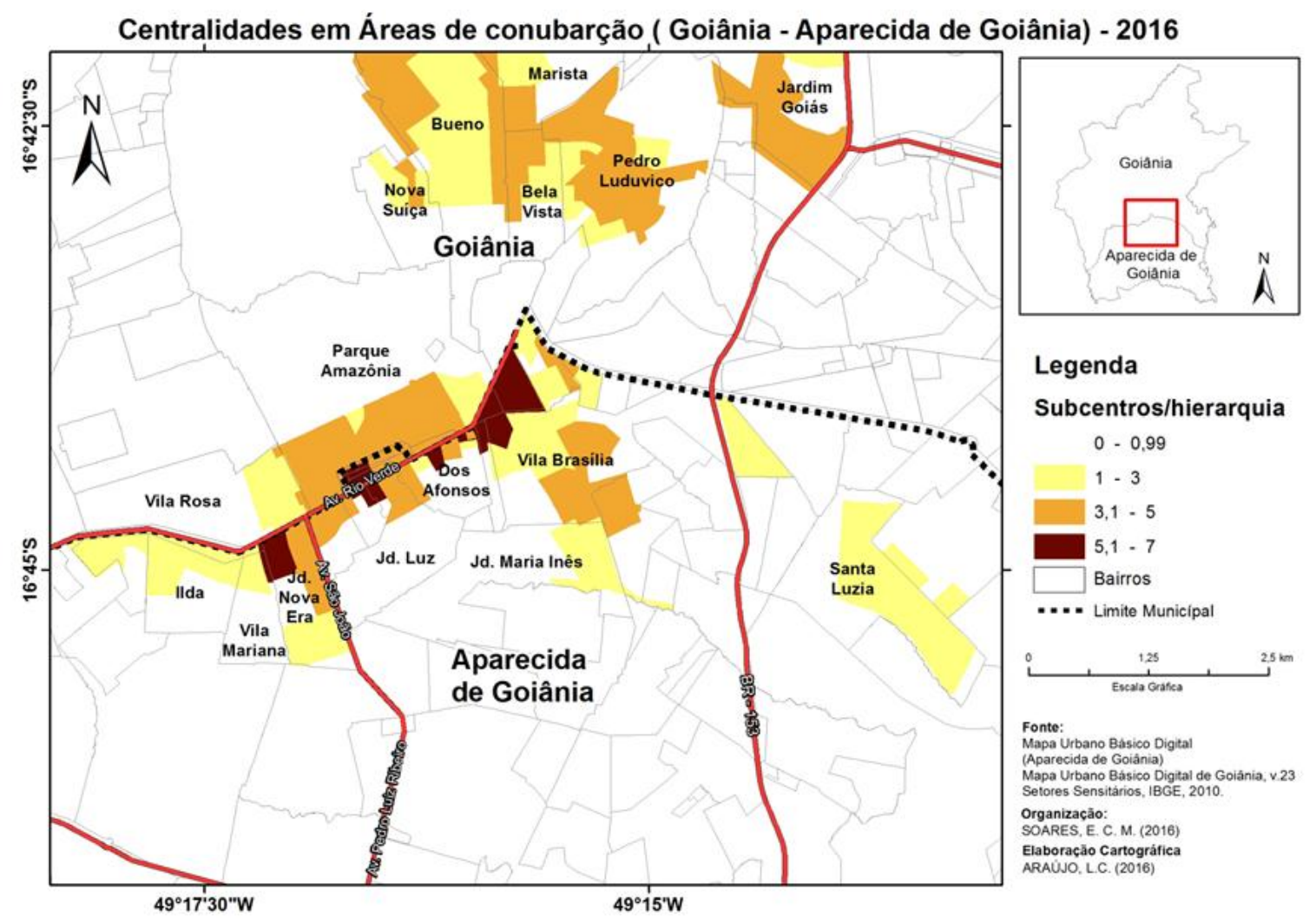

Figura 4: Centralidades Em Conurbação Na Avenida Rio Verde

\subsection{Centralidades da Avenida Rio Verde}

Pela hierarquia estabelecida pelos especialistas, o município apresenta três importantes Centros (Centro histórico - A; Garavelo - E; Av Rio Verde / Buriti Shopping - G), além de importantes subcentros com grande abrangência territorial, como os subcentros da Cidade Livre - $\mathrm{C}$ e da Vila Brasilia - $\mathrm{H}$; e subcentros de bairros, em desenvolvimento (Av. Independência - B, Jardim Tiradentes - D, Bairro Ilda - F, Santa Luzia - I).

Como demonstrado pela pesquisa, a Av. Rio Verde apresenta importantes pontos de centralidades ao longo de sua extensão (Figura 5), com tendência a uma formação linear, lindeira ao eixo viário, nos próximos anos. Esse fato pode ser acelerado com projetos de modificação dos corredores de transporte público coletivo planejados para Goiânia (eixo Norte Sul), com finalização no terminal que se localiza na Avenida Rio Verde, próximo ao shopping center. 
Percebe-se nesse estudo que a formação dessas áreas centrais está, de alguma forma, vinculada à implantação de empreendimentos geradores de viagens (PVGs), como terminais de transporte coletivo, shopping centers, industrias e comércios.

Esse fator pode ser destacado, por não se ter outro shopping do mesmo porte no município, além do fator localização do empreendimento: próximo a Goiânia, à terminais de transporte coletivo, e em uma avenida com características comerciais e estruturais importantes, como explanado anteriormente.

Dito isso, é importante enfatizar a necessidade de o planejamento urbano ser um processo contínuo e permanente das cidades e de realmente ser usado como instrumento destinado a prever e resolver conflitos que afetam a cidade e de distribuição equitativa de benefícios à sociedade.

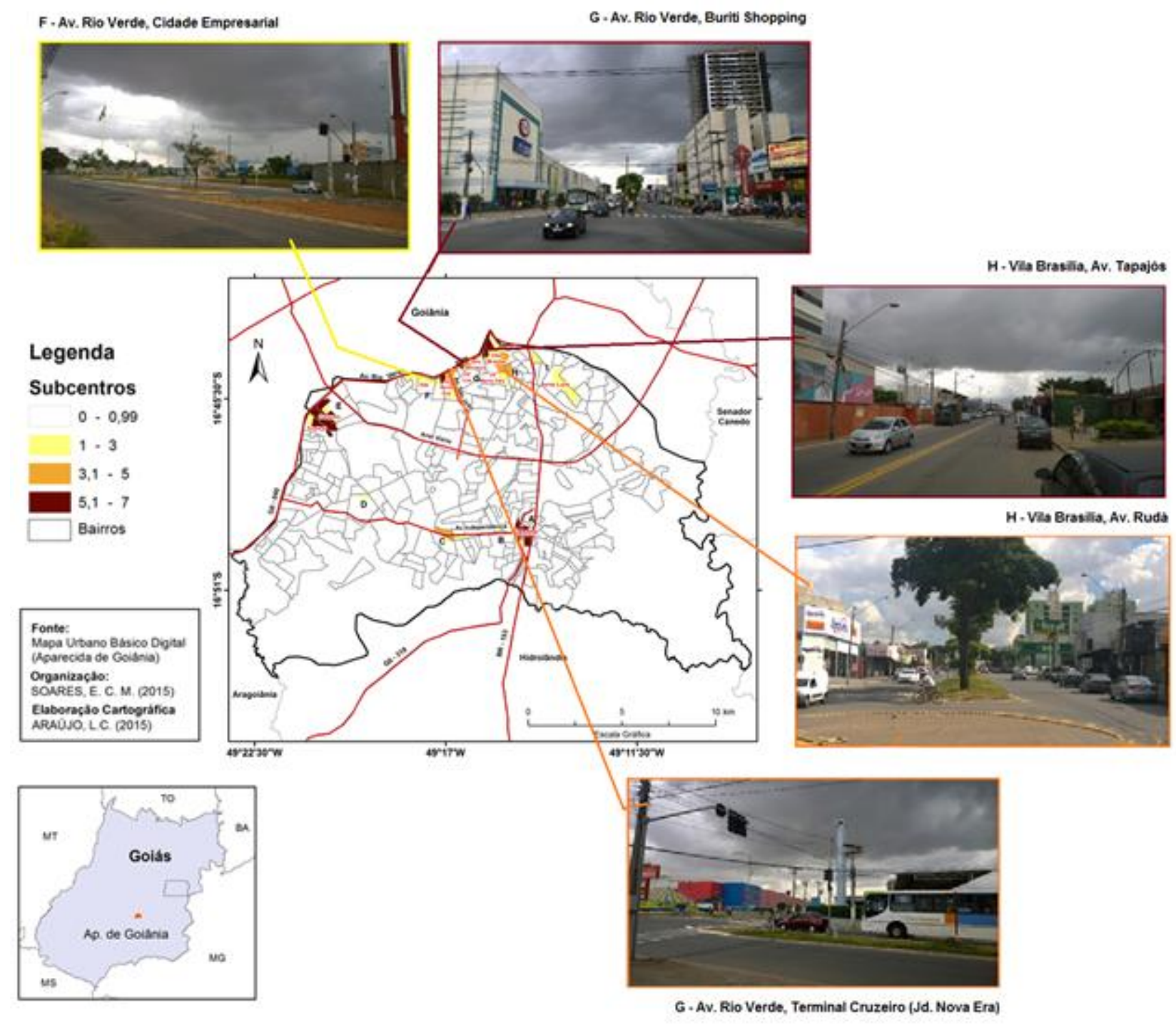

Figura 5: Caracterização Das Centralidades Da Avenida Rio Verde

\section{APLICAÇÃO METODOLÓGICA PARA ANÁLISE DA INFLUÊNCIA DO PVG SHOPPING CENTER NA FORMAÇÃO DA CENTRALIDADE DA AVENIDA RIO VERDE}

O estudo aqui apresentado (Quadro 4) se baseia na análise da ocupação do solo, apresentando mapas correspondentes a 1992, 2006 e 2014, com raio de 500 m do Buriti Shopping. Para complementar a investigação, este estudo avalia ainda o tipo de uso do solo em dois panoramas: o das atividades desenvolvidas no local, ou seja, relativo à caracterização do uso do solo anterior (1992) e posterior (atual 2014) à implantação do PVG Shopping Center. 
Quadro 4: Apresentação Da Metodologia De Análise

\begin{tabular}{|c|c|c|c|c|}
\hline \multicolumn{2}{|c|}{ Etapa } & Metodologia & Ferramenta & Objetivos \\
\hline \multirow{3}{*}{ 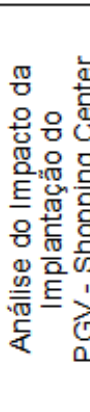 } & 离 & $\begin{array}{l}\text { Exploração espacial da } \\
\text { ocupação da Região. } \\
\text { Definição do raio de } \\
\text { influência: } 500 \mathrm{~m}\end{array}$ & 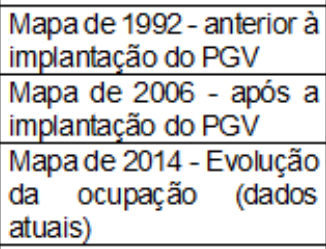 & $\begin{array}{l}\text { Constatar o grau de } \\
\text { ocupação (cheios e } \\
\text { vazios) antes e após a } \\
\text { implantação do PGV } \\
\text { Buriti Shopping }\end{array}$ \\
\hline & \multirow{2}{*}{ 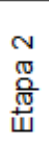 } & \multirow{2}{*}{$\begin{array}{l}\text { Exploração espacial do } \\
\text { tipo de uso do solo / } \\
\text { atividades da Região. } \\
\text { Definição do raio de } \\
\text { influência: } 500 \mathrm{~m}\end{array}$} & Mapa de 1992 & \multirow{2}{*}{$\begin{array}{l}\text { Constatar o tipo de uso } \\
\text { do solo da região, após a } \\
\text { implantação do PGV } \\
\text { Buriti Shopping }\end{array}$} \\
\hline & & & Mapa de 2014 & \\
\hline
\end{tabular}

A inauguração do empreendimento ocorreu no ano de 1996, com área construída de $7.300 \mathrm{~m}^{2}$ e 40 lojas. Hoje apresenta, após quatro reformas e acréscimos, $82.393,80 \mathrm{~m}^{2}$ de área construída, mais de 221 lojas e já se encontra em obras, executando sua quinta expansão, como representado na Tabela 23. Possui um fluxo médio mensal de 1,2 milhões de pessoas (BURITI SHOPPING, 2014).

\subsection{Análise da Ocupação do Solo no Entorno do PGV}

As Figuras 6, 7 e 8 permitem que seja observada, visualmente, a ocupação do solo no entorno do Buriti Shopping. Vale chamar a atenção do leitor sobre os seguintes aspectos:

a. A Figura 6 faz referência ao ano de 1992, anterior à implantação do Shopping que se deu em 1996. Nela estão representados os lotes cheios, de usos diversos, e os vazios, tendo sido considerados assim todo lote livre de edificações, incluindo áreas verdes, de lazer, estacionamentos e campos de futebol. Esses dados estão levantados e analisados através das imagens aéreas da região e da ferramenta SIG. É pertinente notar que o predomínio da cor branca, neste primeiro mapa, permite identificar que antes da implantação do empreendimento, a região possuía muitos vazios urbanos e era pouco fomentada, o que possibilita a afirmação de que a área não estava consolidada antes da implantação do empreendimento;

\section{Mapa com raio de 500m do entorno do Shopping Buriti com lotes vazios - 1992}

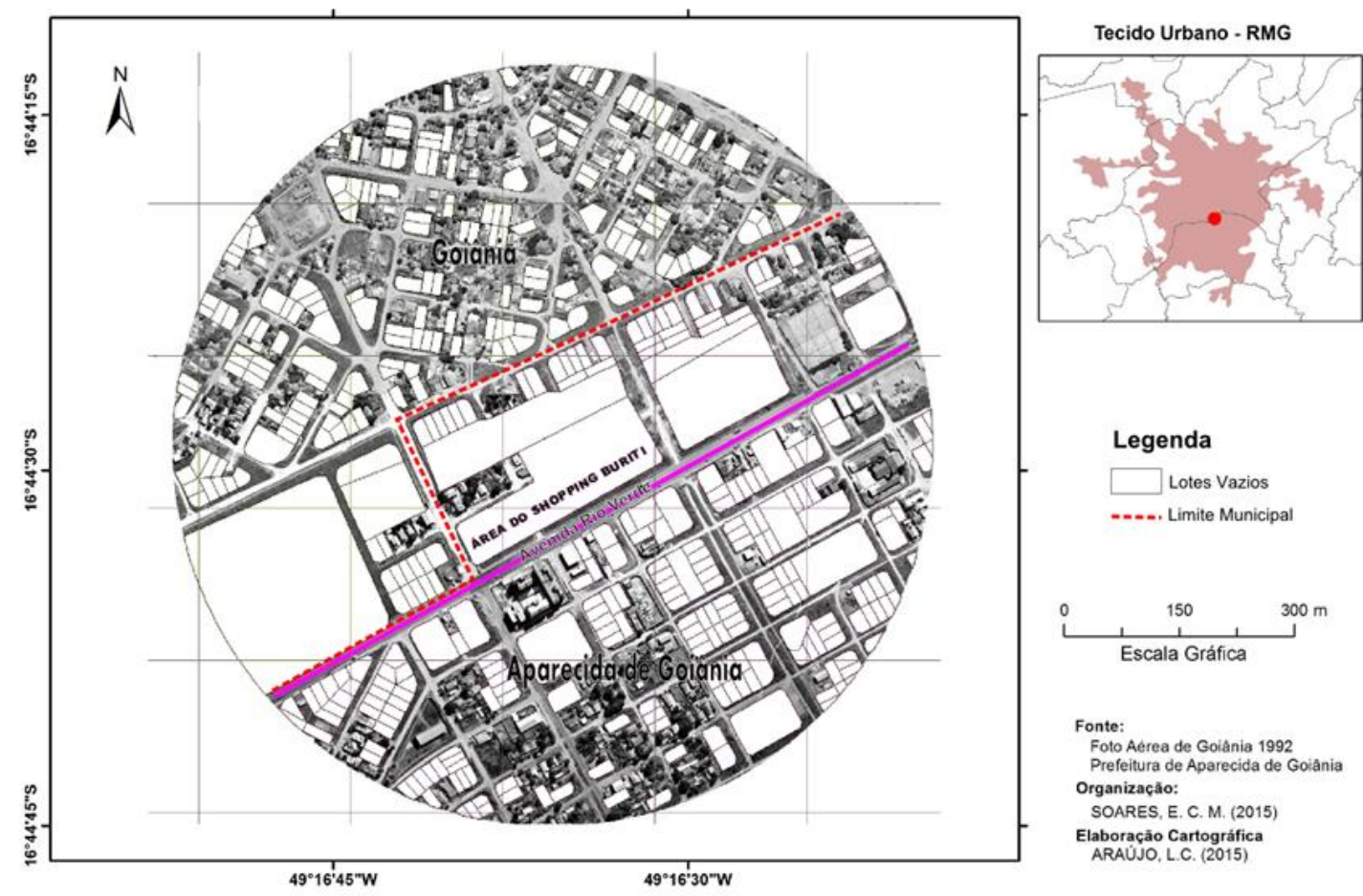

Figura 61: Mapa Com Raio De 500m Do Entorno Do Shopping Buriti Com Lotes Vazios - 1992 
b. O segundo mapa analisado, correspondente à Figura 7, faz referência à imagem aérea do ano de 2006, uma década após a implantação do Buriti Shopping. Sobre a imagem, usando o mesmo procedimento de análise, é perceptível, pela diminuição dos vazios, que a região passou a ser mais ocupada, a apresentar mudança em suas características, com a consequente valorização da área e a qualificação dos serviços prestados. Não se pode negar que a mudança é, também, causada pelo crescimento do Município de Aparecida e pelo aumento do fluxo de pessoas e outros fixos instalados na região, como será visto adiante;

\section{Mapa com raio de 500m do entorno do Shopping Buriti com lotes vazios - 2006}
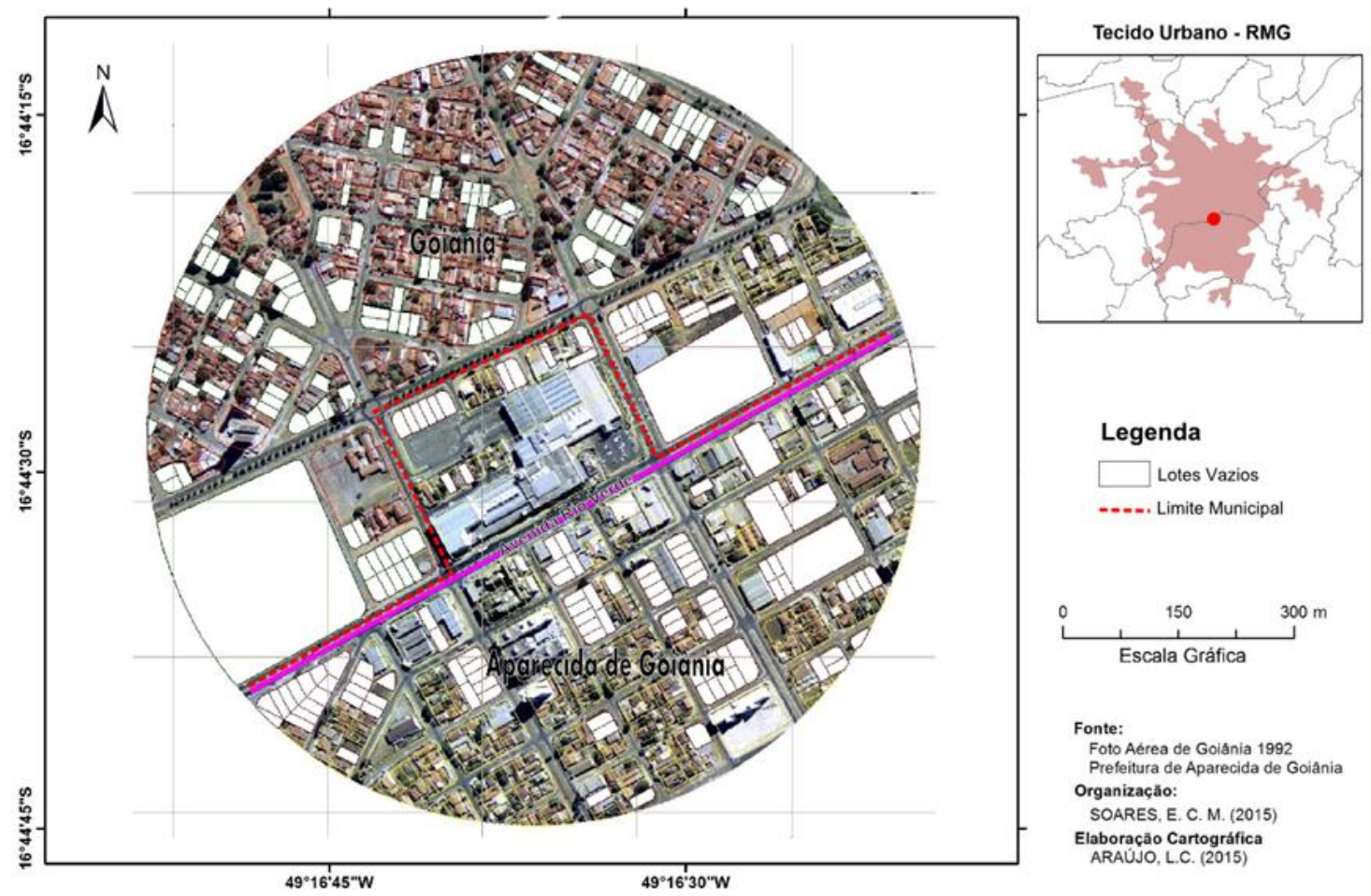

Figura 7: Mapa Com Raio De 500m Do Entorno Do Shopping Buriti Com Lotes Vazios - 2006

c. A Figura 8 faz referência à imagem aérea do ano de 2014, dezoito anos depois da inauguração do empreendimento, e após a conclusão de suas quatro expansões. A região se mostra consolidada no ano de 2006, mas permanece crescendo nos aspectos de uso e ocupação do solo. Também é interessante observar, pela imagem, que algumas áreas vagas estavam sendo utilizadas como estacionamentos. Esse fato pode ser relacionado, segundo Kneib (2012) com o aumento na geração de viagens à região, intensificando o uso do veículo individual relacionadas ao PGV, neste caso, o Buriti Shopping. 
Mapa com raio de 500m do entorno do Shopping Buriti com lotes vazios - 2014

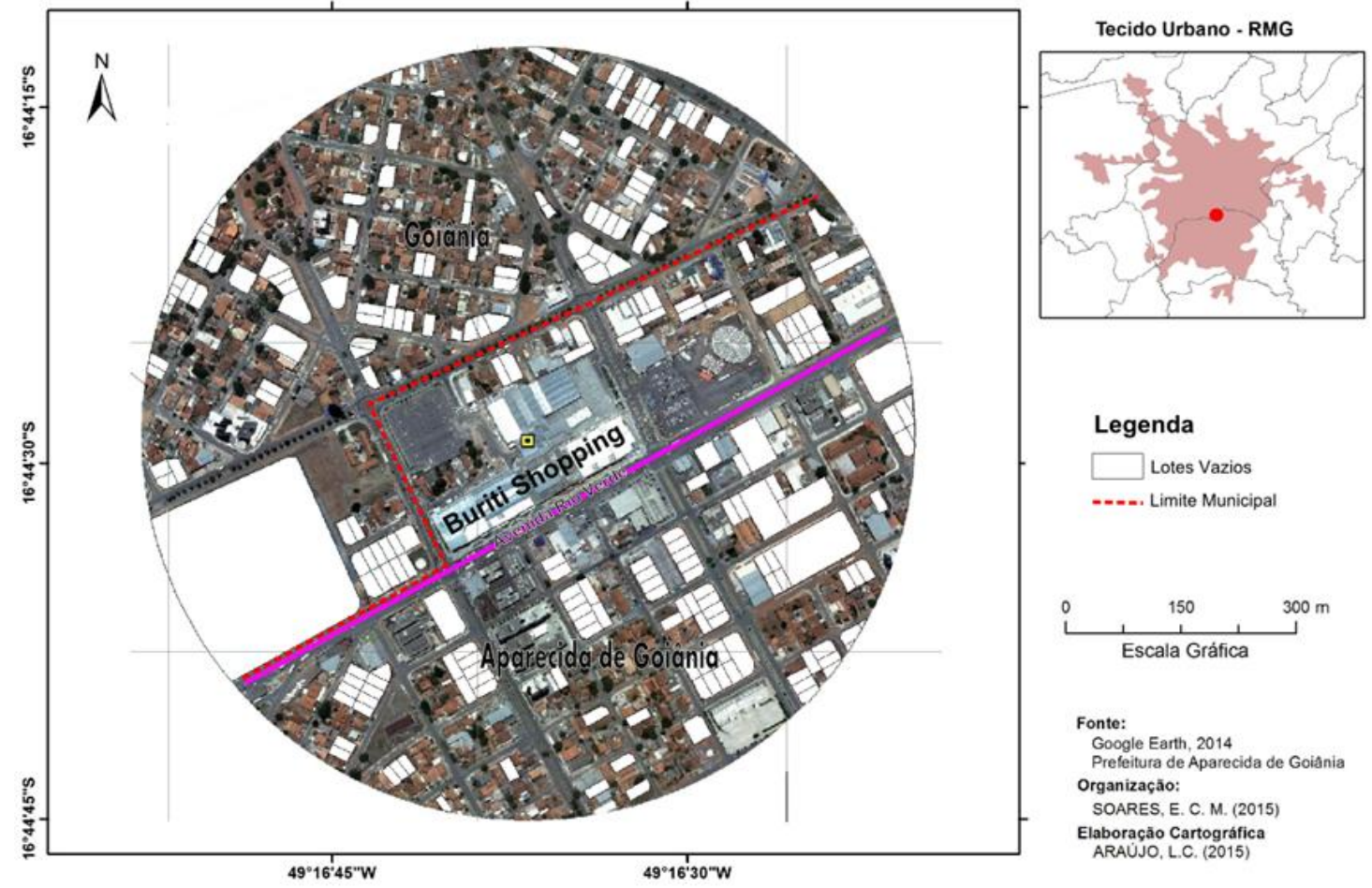

Figura 82: Mapa Com Raio De 500m Do Entorno Do Shopping Buriti Com Lotes Vazios - 2014

Segundo os dados apresentados abaixo, no Quadro 5 e Figura 9, a primeira imagem, 1992, mostra em Goiânia um total de 180 áreas vagas e em Aparecida 227; a segunda, 2006, Goiânia com 108 e Aparecida 134 e a terceira, 2014, Goiânia apresenta 102 e Aparecida 124 áreas vagas. Isso permite dizer que, durante a primeira década da ocupação do empreendimento, a região teve um aumento expressivo em sua ocupação.

Quadro 5: Ocupação Do Solo No Entorno Do Empreendimento (1996 A 2014 - Raio De 1000m): Áreas Vazias.

\begin{tabular}{|l|c|c|c|c|c|c|c|c|c|}
\cline { 2 - 9 } \multicolumn{1}{c|}{} & \multicolumn{4}{c|}{1992} & \multicolumn{3}{c|}{2006} & \multicolumn{3}{c|}{2014} \\
\hline \multicolumn{1}{|c|}{ Variável } & Goiânia & Aparecida & Total & Goiânia & Aparecida & Total & Goiânia & Aparecida & Total \\
\hline $\begin{array}{l}\text { Lotes } \\
\text { Vagos }\end{array}$ & 180 & 227 & 407 & 108 & 134 & 242 & 102 & 124 & 226 \\
\hline Área $\left(\mathrm{m}^{2}\right)$ & $181.967,80$ & $193.446,20$ & 375414 & $95.845,35$ & $92.269,84$ & 188115,19 & $92.115,81$ & $71.997,73$ & 164113,54 \\
\hline
\end{tabular}

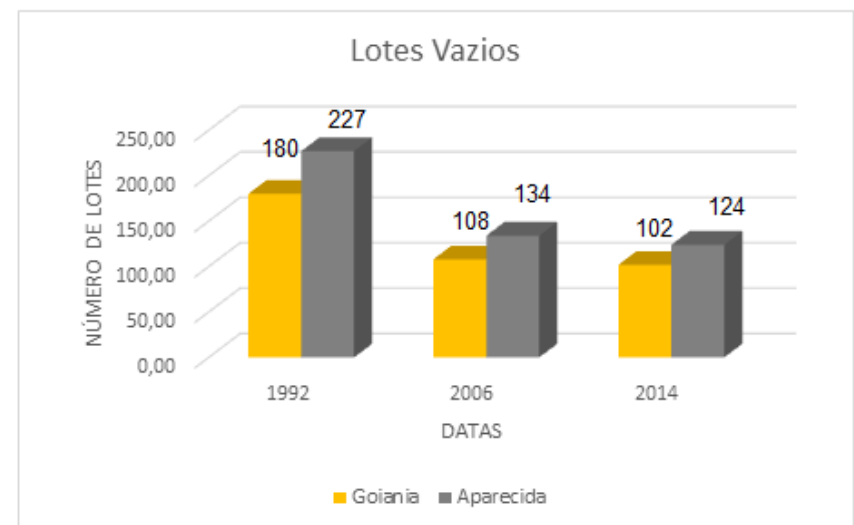

Figura 9: Ocupação Do Solo No Entorno Do Empreendimento (1996 A 2014 - Raio De 1000m) 


\subsection{Caracterização do Uso do Solo na Região de Influência do PGV Shopping Center}

No que diz respeito às atividades econômicas, Pinto (2009) afirma que em 2007 existiam 199 estabelecimentos de comércio, nos bairros que fazem parte do entorno do Buriti Shopping e que desses $71,8 \%$ se encontravam dentro do Shopping. Na época, as atividades de comércio dessa centralidade representavam $4 \%$ do total da cidade de Aparecida de Goiânia ${ }^{1}$.

Ao se referir ao que tange à prestação de serviço, a pesquisa de Pinto (2009) cita que a maior parte dessa atividade (presente em toda a região) também se encontrava dentro do Shopping, sendo o percentual de $51,20 \%$ dos 248 estabelecimentos de serviços.

Os mapas a seguir (Figuras 10 e 11) abordam o uso do solo no entorno imediato do Empreendimento em estudo. A partir de imagens de satélite da região, somadas às informações coletadas in loco e trabalhandoas posteriormente em um software SIG, resultaram os dois recortes temporais.

a. A Figura 10, representando a situação de 1992, com raio de abrangência de 500 metros, destacando o estudo das áreas ocupadas segundo o tipo de atividade (uso do solo);

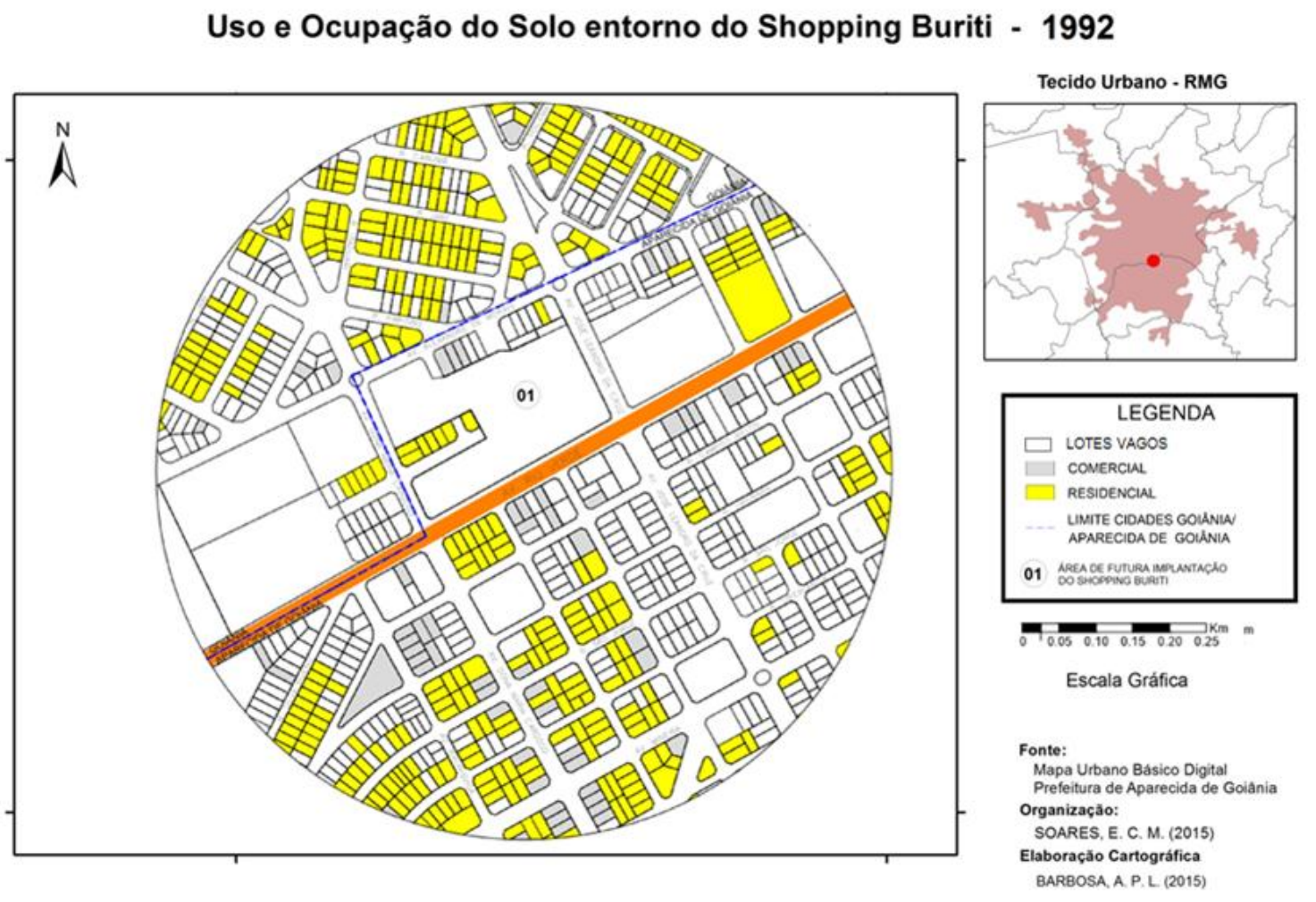

Figura 10: Mapa De Uso Do Solo Com Raio De 500m Do Shopping Buriti - 1992

b. A Figura 11, representando a situação de 2014, com raio de abrangência de 500 metros, destacando os valores de seus respectivos terrenos e não de área construída da edificação.

\footnotetext{
${ }^{1}$ As atividades comerciais fora do shopping que mais predominam são lojas de vestuário, com 4,5\% do total; Drogarias (3\%); de equipamentos de informática (3\%); Pet shop (2\%); papelarias (2\%); concessionárias de veículos (2\%); distribuidora de gás, bebida e água (2\%); além de casas de carnes (1,5\%); casas de móveis; supermercados; revistarias; e vidraçarias. (PINTO, 2009, p. 143).
} 


\section{Uso e Ocupação do Solo entorno do Shopping Buriti - 2014}
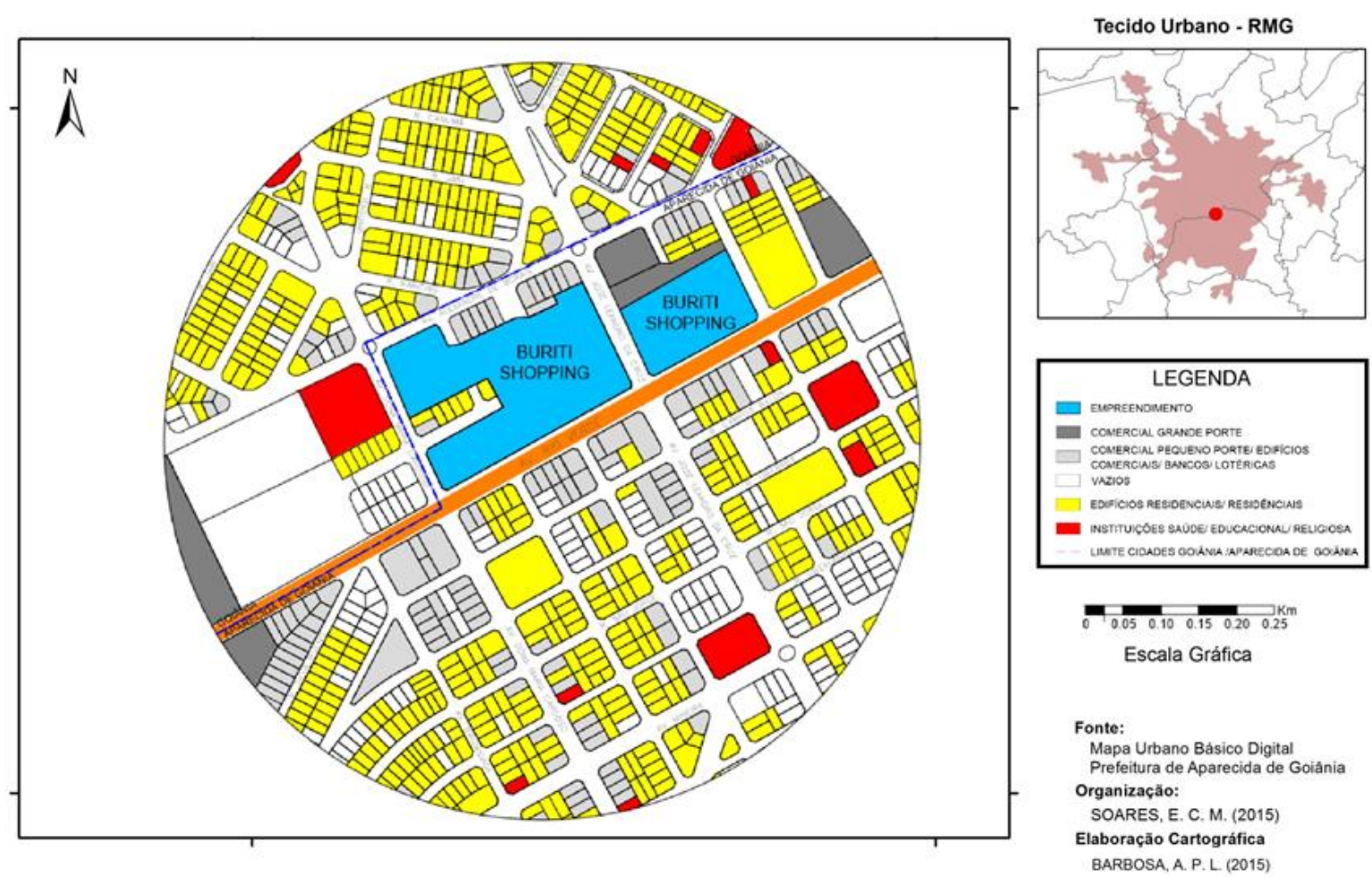

Figura 113: Mapa De Uso Do Solo Com Raio De 500m Do Shopping Buriti - 2014

Após a análise das imagens, apresentadas as situações dos usos do solo anterior e posterior à implantação do PGV Buriti Shopping, é possível concluir o mesmo ocorrido no estudo de Kneib (2012): grande aumento do número de atividades comerciais na região, principalmente lindeiras ao Shopping, cercada por duas avenidas de grande movimento. Sem dúvida houve um acréscimo das áreas construídas, residenciais e comerciais/institucionais, assim como um decréscimo das áreas vagas, para todos os períodos posteriores à construção do empreendimento. No período de 1992 a 2014, constata-se um aumento na área construída superior a $200 \%$, sendo que, relativo às atividades residenciais, o aumento foi pouco maior que $50 \%$. Em compensação, as atividades comerciais, desconsiderando o próprio Shopping, tiveram aumento de quase $1000 \%$. Essas considerações podem ser melhor conferidas por meio do Quadro 6 e da Figura 12, que indicam os dados analisados.

A área abordada nos dados tabelados se referem à área de terreno (não área construída, que engloba diferenciação de número de pavimentos), tendo sido contabilizada pela ferramenta SIG.

Quadro 6: Tipos De Ocupação Do Solo No Entorno Imediato Do Shopping , Com Raio De 1000 Metros, (1992 E 2014) - Área Total De Estudo: 196.246,57 M²

\begin{tabular}{|l|c|c|c|c|c|c|c|c|}
\cline { 2 - 10 } \multicolumn{1}{c|}{} & \multicolumn{4}{c|}{1992} & \multicolumn{4}{c|}{2014} \\
\hline $\begin{array}{c}\text { Variável (Área } \\
\mathbf{m}^{2} \text { ) }\end{array}$ & Goiânia & Aparecida & Total & $\%$ & Goiânia & Aparecida & Total & \% \\
\hline Residencial & $13.735,33$ & $10.820,76$ & $24.556,09$ & 12,51 & $34.685,61$ & $3.929,46$ & $38.615,07$ & 19,67 \\
\hline Comercial & 0 & $2.581,86$ & $2.581,86$ & 1,31 & $6.471,20$ & $20.310,67$ & $26.781,87$ & 13,64 \\
\hline Institucional & 0 & 0 & 0 & 0 & 0 & $4.458,24$ & 4458,24 & 2,27 \\
\hline Estacionamentos & 0 & 0 & 0 & 0 & 0 & $17.337,24$ & 17337,24 & 8,83 \\
\hline
\end{tabular}




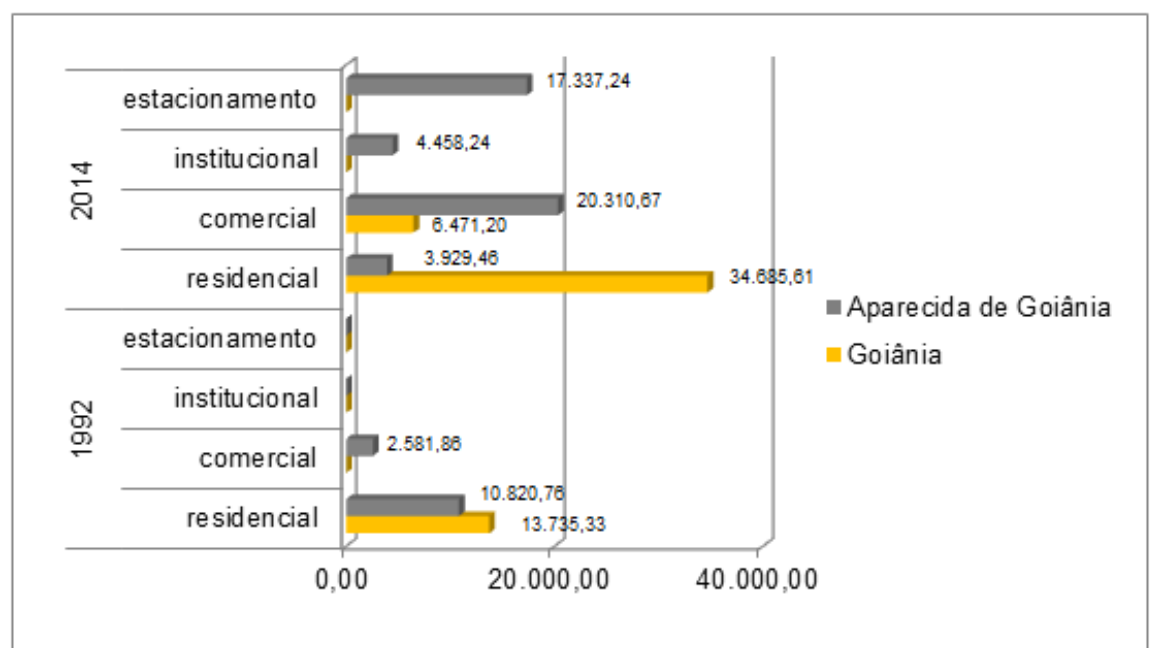

Figura 12: Gráfico Da Evolução Do Uso E Ocupação Do Solo Do Entorno Do Empreendimento.

Hoje o panorama já se encontra diversificado por vários outros empreendimentos instalados na região, inclusive os de grande porte, como hipermercados e concessionárias. Embora o shopping seja o principal centro comercial, diversos serviços de grande importância, principalmente bancários, também se instalaram ao longo da Avenida Rio Verde, como foi abordado no Capítulo III desta dissertação.

\subsection{Análise da Acessibilidade da Região em Estudo}

Para a análise da acessibilidade na região, destaca-se um aspecto: o terminal de transporte coletivo, localizado no raio de influência imediata do Buriti Shopping, considerado como outro PGV da mesma região. Av. Rio Verde o mais importante eixo comercial de Aparecida de Goiânia. Além do Empreendimento estudado, corrobora com o grau de importância da Av. Rio Verde o fato de ela ser: parte da rota de distribuição do fluxo para os demais bairros da região sul e oeste do Município de Aparecida de Goiânia; possibilitar o acesso para os terminais do transporte público coletivo Vila Brasília, Cruzeiro, Garavelo e Veiga Jardim e a alguns terminais de Goiânia e importantes avenidas que compõem eixos estruturadores como as Avenidas 85 e T63; além de dar entrada a importantes eixos viários como às BRs 153 e 060, à GO 040 e ao Anel Viário (Figura 13).

Ressalta-se a fragmentação existente no espaço intraurbano de Aparecida, sendo grande parte dos terminais de ônibus localizados no perímetro urbano conurbado com a capital, o que facilita o deslocamento para a mesma, e não para o interior do território municipal.

Observa-se na figura 13 que nenhum dos terminais tem uma via estruturante que faz a ligação do Terminal Araguaia (na região do Centro) com os demais terminais municipais, sendo o acesso ao mesmo por diferentes vias, inclusive vias de acesso local.

De acordo com o Observatório das Metrópoles (2010), o IBEU (Índice de Bem-Estar Urbano) de Aparecida de Goiânia é de 0,678 (podendo ser classificado entre 0,001 e 1,0), composto por: índice de mobilidade Urbana - 0,668; condições ambientais urbanas - 0,906; condições habitacionais urbanas - 0,788; atendimento de serviços coletivos urbanos - 0,56; Infraestrutura urbana - 0,468. Esse índice coloca Aparecida de Goiânia (o terceiro maior PIB do Estado de Goiás em 2010, de acordo com o Instituto Mauro Borges) em 17ํ lugar no ranking entre os 20 municípios da Região Metropolitana de Goiânia. De acordo com o relatório, a região de estudo apresenta o segundo maior índice da RMG e o melhor do município de Aparecida de Goiânia, com IBEU entre 0,9 e 0,801.

Relacionados à mobilidade e acessibilidade, o estudo citado apresenta os indicadores observados para a classificação do índice de acessibilidade, aplicado ao espaço urbano, no quesito voltado à infraestrutura urbana, sendo: iluminação pública, pavimentação asfáltica, calçadas, meio-fio / guia, bueiro ou boca de lobo, rampa para cadeirantes e logradouros. Aparecida está entre os 07 piores municípios da RMG, possuindo valores intermediários e inferiores em quase todo o território urbano, a região de estudo apresenta índice entre 0,7 e 0,501 . 
Terminais de Transporte Coletivo nas proximidades da Av. Rio Verde - 2015

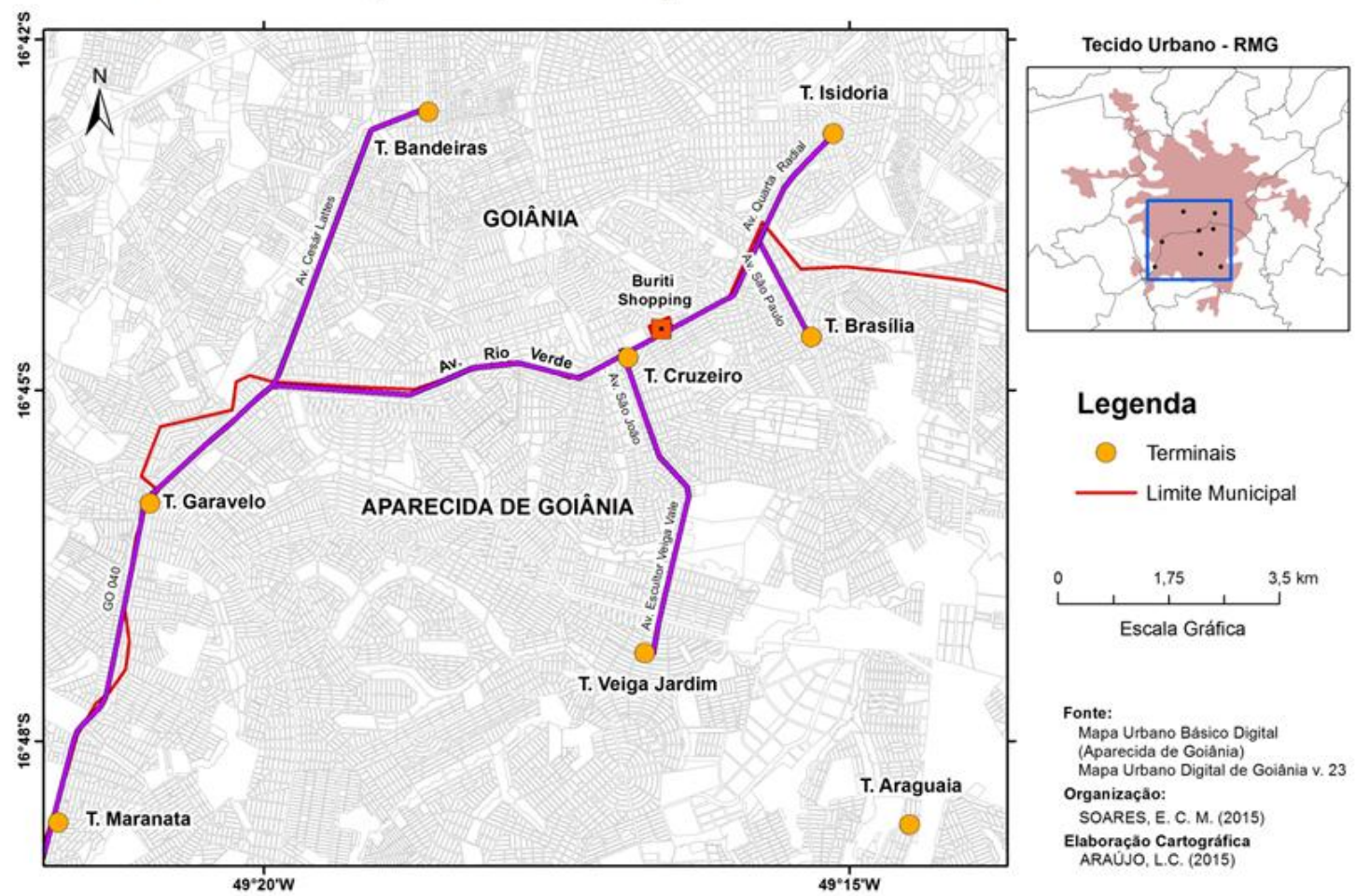

Figura 134: Terminais De Transporte Coletivo (E Principais Vias De Acesso), Nas Proximidades Da Avenida Rio Verde

Sobre a mobilidade urbana, o indicador considerado é o tempo de deslocamento casa-trabalho. Foi considerado adequado o tempo de até uma hora gasto no trajeto de ida ou volta entre o domicílio de residência e o local de trabalho. Aparecida de Goiânia apresentou 04 índices, sendo a região de estudo inserida no segundo melhor índice (entre 0,9 e 0,801) apresentado no estudo, sendo o mesmo o melhor índice apresentado no espaço intraurbano do município de Aparecida de Goiânia. Observa-se que esses índices indicam que o local estudado, inserido em uma área de conurbação urbana, possui características diferenciadas de todo o território urbano do município onde está inserido.

\section{CONSIDERAÇÕES FINAIS}

A pesquisa iniciou-se com uma análise em escala micro-regional (intraurbana), envolvendo entorno imediato do empreendimento (Shopping Center), considerado até então o maior influenciador da transformação ocorrida nos bairros próximos a ele; para, futuramente, evoluir para uma análise em escala macro regional. A partir de então, verificou-se a confirmação da abordagem do estudo do processo de formação e ocupação do território, dando ênfase à identificação e caracterização (do grau de importância) de centralidades existentes nos municípios envolvidos. Ressalta-se que a área de estudo, na porção pertencente ao município de Aparecida de Goiânia, possui características distintas das demais regiões territoriais do município, destacando-se pela presença de infraestrutura urbana, tipologia das edificações, verticalização e adensamento populacional, existência de grandes comércios e prestações de serviços.

Sobre os conteúdos abordados inicialmente, concluiu-se que Aparecida de Goiânia se desenvolveu próximo a capital Goiânia com grande processo de crescimento, como descreve Villaça (2001), com muitas características comuns observadas nas metrópoles brasileiras como São Paulo, Rio de Janeiro, Porto Alegre, entre outras; crescimento que gerou o surgimento de vários centros urbanos no território da cidade, áreas de conurbação (divididas pelo autor em quatro aspectos e estilos de ocupação) e com grande segregação espacial. Devido à grande quantidade de vazios urbanos e à extensa área territorial urbana de Aparecida, pode-se dizer que esses centros se desenvolveram divergentemente, tanto no aspecto do tamanho e importância quanto em seu raio de abrangência.

Observa-se que uma característica presente no desenvolvimento urbano do município de Aparecida de Goiânia é a existência de periferias nas bordas e franjas, mas também no centro do território municipal, 
enquanto que as margens periféricas, em conurbação com a capital, desenvolveram-se com características de centralidades.

Aparecida nas últimas décadas sofreu grandes transformações, não somente no que diz respeito ao aumento da infraestrutura, da oferta de serviços, do estabelecimento de polos industriais, comerciais e de prestação de serviços, mas todos esses fatores tiveram como consequência uma reestruturação urbana, com a formação de novas centralidades, a valorização do solo urbano. Neste caso específico, uma das centralidades aparecidenses se destaca sob influência da conurbação ao longo do eixo territorial da Avenida Rio Verde. A região do Buriti Shopping se configurou primeiramente como centralidade com a construção do mesmo, trazendo à região bancos, hipermercados, concessionárias, além de estar entre dois terminais do município (Cruzeiro e Vila Brasília), facilitando o acesso e fluxo da população. A Avenida Rio Verde ainda possibilita o acesso direto, à Oeste, aos condomínios horizontais Jardins Viena e Jardins Mônaco, à Cidade Empresarial e ao Terminal Garavelo (GO 040) e Anel viário, por isso considerada anteriormente como a principal via comercial do município. À leste permite acesso ao Terminal Vila Brasília e à Av. São Paulo (que faz a ligação à BR 153). A região da Vila Brasília se caracteriza também pela verticalização.

$\mathrm{Na}$ região pesquisada, observa-se claramente, que antes da implantação do empreendimento (Shopping Center), a mesma era caracterizada como a maior parte do território urbano do município: com grandes vazios urbanos. Observou-se que a implantação do empreendimento ocasionou um processo de alteração da ocupação da região e do uso do solo, ocasionando a atração de diversificados tipos de comércios e serviços, mudando as características no meio ambiente urbano no local.

A centralidade mais evidente da região norte de Aparecida se encontrava na Vila Brasília, sendo que a mesma hoje, de acordo com a pesquisa, possui o mesmo grau de importância da centralidade da Avenida Rio Verde. Os instrumentos propostos pelo Plano Diretor do município para a região, citados nessa pesquisa, propuseram a ocupação da mesma, impulsionando também seu desenvolvimento e crescimento como centralidade.

Vale chamar a atenção para o fato de que, nesta pesquisa, ao ter sido verificada a centralidade da área estudada, também foram averiguadas as transformações da dinâmica intraurbana que ocorreram na organização do tecido urbano. Como foi apresentado, a área teve a implantação de empreendimento de grande porte, especificamente o Buriti Shopping, como fator de influência direta na ocupação da região. Na verdade, uma forma espacial, resultante do processo de reprodução das funções centrais em um setor periférico da Cidade.

Para o problema proposto, acredita-se terem sidos respondidos todos os questionamentos realizados, sendo a região de estudo comprovadamente, se consolidado como uma centralidade (mesmo localizada em região limítrofe do território municipal); tendo sido influenciada pelo crescimento e expansão de Goiânia, e consolidada a partir da implantação do PGV - Shopping Center; sofrendo expressiva transformação nas características de uso e ocupação do solo; cuja localização e abastecimento do transporte coletivo e de terminais de ônibus corroboraram com o crescimento da região, bem como a infraestrutura viária existente.

A hipótese foi confirmada, sendo a implantação do PGV (Shopping Center) considerada a mais impactante, e talvez o mais importante fator de transformação da região estudada, tendo sido pivô dos demais fatores abordados na pesquisa, inclusive da ocupação da parcela pertencente ao município de Goiânia (já em processo de crescimento da região sul). Constatou-se a consolidação da centralidade da Avenida Rio Verde, tanto pelo método dos especialistas aplicado nos municípios envolvidos, quanto pela análise espacial sistemática realizada no entorno do empreendimento Buriti Shopping. Para tal, percorreu-se todo o caminho proposto nos objetivos específicos, desde uma abordagem do referencial teórico, do processo histórico de expansão urbana dos municípios, da conceituação e aplicação da metodologia dos especialistas e da análise espacial e dos planos urbanísticos propostos.

Não se pode finalizar, atribuindo destaque para a necessidade de um planejamento integrado, principalmente para os municípios que estão inseridos em regiões metropolitanas, no caso desse estudo, a inexistência de um Plano Metropolitano (RMG), que dê diretrizes para as regiões em área de conurbação com a Metrópole, Goiânia, bem como diretrizes para que haja continuidade do processo de planejamento urbano, atribuindo uma cidade mais igual e social, com a presença dos mesmos serviços e infraestrutura existentes nas regiões conurbadas com a capital no interior do território das cidades inseridas neste contexto. 


\section{BIBLIOGRAFÍA}

BENEVOLO, Leonardo. História da Cidade. São Paulo: Perspectiva. 2005.

BIRD, J. (1977) Centrality and Cities. London, Routledge Direct Editions.

BURITI SHOPPING (2014) Relatório Administrativo. Goiânia, GO

CAMILO, Janaína De Holanda. O Preço Da Terra E O Plano Diretor De Aparecida De Goiânia (2001-2014). Dissertação de Mestrado, PUC GO, 2014.

CASTELLS, Manuel. A questão urbana. São Paulo: Paz e Terra, 1972

CORRÊA, R.L. 1995. O espaço urbano. 3ª ed. São Paulo: Ática.

DENATRAN - Departamento Nacional de Trânsito. (2001). Manual de Procedimentos para o Tratamento de Polos Geradores de Tráfego. Ministério da Justiça - Brasília, DF.

FERRARI, Célson. Curso de Planejamento Municipal Integrado. 2ª Edição, Editora São Paulo. 1979.

GEDDES, Patrick. Cidades em Evolução. Tradução: Maria José Ferreira de Castilho. Campinas: Papirus, 1994.

GONÇALVES, Fabio Dos Santos; LEMOS, Diana Scabelo Da Costa Pereira Da Silva; KNEIB, Érika Cristine; PORTUGAL, Licinio da Silva. Caracterização de Pólos Geradores de Viagens. PORTUGAL, L. Da S. Polos Geradores de Viagens Orientados à Qualidade de Vida e Ambiental. Rio de Janeiro. Editora Interciencia. 2012.

GONÇALVES, Fabio dos Santos. Classificação dos Pvgs e sua Relação com as Técnicas de Análise de Impactos Viários. Dissertação de Mestrado, UFRJ, 2012

GOLDNER, L. G. (1994). Uma Metodologia de Avaliação de Impactos de Shopping Centers sobre o Sistema Viário Urbano. Tese de Doutorado, COPPE/UFRJ. Rio de Janeiro, RJ.

GOTTDIENER, Mark. A produção social do espaço urbano. São Paulo: Edusp, 1997.

GRANDO, L. A. (1986). A Interferência dos Pólos Geradores de Tráfego no Sistema Viário: Análise e Contribuição Metodológica para Shopping Centers. Tese de Mestrado em Engenharia de Transportes, COPPE/UFRJ. Rio de Janeiro, RJ.

IBGE (2013) Cidades. Instituto Brasileiro de Geografia e Estatística. Disponível em www.ibge.gov.br. Acesso em outubro de 2015.

KNEIB, E. C. (2004), Caracterização de empreendimentos geradores de viagens: contribuição conceitual à análise de seus impactos no uso, ocupação e valorização do solo urbano. Tese de M.Sc., Engenharia de Transportes, ENC/FT/UnB, Brasília, DF, Brasil.

KNEIB, Erika Cristine. (2008) Subcentros urbanos: contribuição conceitual e metodológica à sua definição e identificação para planejamento de transportes. Tese de doutorado em Transportes, Publicação T. TD - 002A/2008, Departamento de Engenharia Civil e Ambiental, Universidade de Brasília, Brasília, DF.

KNEIB, Erika Cristine. 2012. Polos Geradores de Viagens, Centralidades e seus Impactos na Mobilidade Urbana.

KNEIB, Érika Cristine; TEDESCO, Giovanna Megumi Ishida; BARROS, Ana Paula Borba Gonçalves; PAIVA, Mariada. PGVs e Centralidades: Impactos na Escala Urbana e Metropolitana. PORTUGAL, L. Da S. Polos Geradores de Viagens Orientados à Qualidade de Vida e Ambiental. Rio de Janeiro. Editora Interciencia. 2012.

KNEIB, Erika Cristine. Mobilidade Urbana e Qualidade de Vida: do Panorama Geral ao Caso de Goiânia. Revista Ufg / Julho 2012 / Ano XIII № 12.

LEFEBVRE, Henry. De lo rural a lo urbano. Barcelona. Ed. 62, 1978.

MARICATO, E. T. M. (2003). Metrópole, Legislação e Desigualdade. Estudos Avançados 17 (48). 2003.

MORAES, Lucia Maria. A segregação Planejada: Goiânia, Brasília e Palmas. Goiânia. Ed. UCG. 2006.

PANERAI, Pilippe. Análise Urbana. Editora UNB. 2006.

PASQUALETTO, Antônio; SOUZA, Fábio. A Mobilidade Em Goiânia Sob A Ótica Do Transporte Coletivo. 2014

PINTO, José C. V. Fragmentação da metrópole: constituição da região metropolitana de Goiânia e suas implicações no espaço intraurbano de Aparecida de Goiânia. Dissertação de Mestrado. IESA, Universidade Federal de Goiás, 2009.

PORTUGAL, L. S. \& GOLDNER, L. G., (2003). Estudo de Polos Geradores de Tráfego e de seus Impactos nos Sistemas Viários de Transportes. Editora Edgard Blücher.

Prefeitura Municipal de Aparecida de Goiânia (2002). Lei Complementar no 004/2002, de 30 de Janeiro de 2002. Dispões sobre o Planejamento Municipal Sustentável, sobre o Plano Diretor do Município de Aparecida de Goiânia, e dá outras providências.

Prefeitura Municipal de Aparecida de Goiânia (2008). Lei Complementar no 017/2008, de 13 de outubro de 2008. Altera a Lei Complementar no 005 de 30 de janeiro de 2002, que dispõe sobre o zoneamento, uso e ocupação do solo da área urbana e rural do Município, cria o conselho Municipal de Zoneamento e dá outras providências.

RAIA JR Archimedes Azevedo. Acessibilidade e Mobilidade na estimativa de um índice potencial de viagens utilizando redes neurais artificiais e Sistemas de Informações Geográficas. Dissertação de Mestrado. Universidade de São Paulo, São Carlos, SP, 2000.

RIBEIRO, Maria Eliana Jubé. Goiânia: os planos, a cidade e o sistema de áreas verdes.1. Ed. Goiânia: Ed. UCG, 2004.

RIBEIRO, Luiz César de Queiroz; RIBEIRO, Marcelo Gomes. Índice de Bem-Estar Urbano IBEU. Rio de Janeiro, Observatório das Metrópoles, 2013

SANTOS, Milton. A urbanização brasileira. 1a Ed. São Paulo: Hucitec, 1993

SERPA, Angelo. Lugar e Centralidade em um Contexto Metropolitano. FANI, Ana; SOUZA, Marcelo Lopes; SPOSITO, Maria Encarnação Beltrão (org). A produção do Espaço Urbano: Agentes e processos, escalas e desafios. Ed. Contexto. 2014 
SOUZA, Marcelo Lopes de. Mudar a cidade: uma introdução crítica ao planejamento e a gestão urbanos. Rio de Janeiro: Bertrand Brasil, 2006.

SPOSITO, Maria Encarnação Beltrao. Cidades A Gestão do Território e as Diferentes Escalas da Centralidade Urbana. In: II ENCONTRO NACIONAL DA ANPEGE. Rio de Janeiro. 1997.

SPOSITO, Maria Encarnação B. Cidades Médias: Reestruturação das cidade e reestruturação urbana. SPOSITO, Maria Encarnação B. Cidades Médias - espaços em transição. São Paulo. Expressão Popular, 2007.

VILLAÇA, F. Espaço intra-urbano no Brasil. São Paulo: Studio Nobel: FAPESP: Lincoln Institute, 2001.

VOLOCHKO, Danilo. Nova Produção das Periferias Urbanas e Reprodução do Cotidiano. FANI, Ana (org). Crise Urbana. Ed. Contexto, 2015

WRIGHT, James T. C. GIOVINAZZO, Renata A. Delphi - Uma Ferramenta de Apoio ao Planejamento Prospectivo. Caderno de Pesquisas em Administração.v. 01, no 12, $2^{\circ}$ trimestre/2000 